\title{
Earthquake sequence in the NE Lut, Iran: observations from multiple space geodetic techniques
}

\author{
M. Marchandon, ${ }^{1}$ M. Vergnolle, ${ }^{1}$ O. Cavalié, ${ }^{1}$ H. Sudhaus ${ }^{2}$ and J. Hollingsworth ${ }^{3}$ \\ ${ }^{1}$ CNRS, Observatoire de la Côte d'Azur, IRD, Université Côte d'Azur, Géoazur Valbonne, France. E-mail: marchandon@geoazur.unice.fr \\ ${ }^{2}$ Christian-Albrechts-University Kiel, Department of Geosciences, Kiel, Germany \\ ${ }^{3}$ ISTerre, Université Grenoble Alpes, Grenoble, France
}

Accepted 2018 September 4. Received 2018 June 26; in original form 2018 February 05

\begin{abstract}
SUMMAR Y
An increasing number of observations supports temporal clustering behaviour of earthquakes within fault systems. As earthquake occurrence is mainly controlled by the crustal stresses, it is crucial to determine their spatio-temporal evolution to understand the generation of catastrophic seismic sequences. A possible way to constrain these variations is to measure the surface displacement field induced by seismic sequences. However, the observation time of modern satellite geodesy (InSAR/GPS) is short compared to the duration of an earthquake sequence. Thus, the goal of this paper is to extend the temporal range of observations of a seismic sequence. We focus on the largest earthquakes of the 1936-1997, Northeast Lut, Iran, sequence that is composed of $11 M_{\mathrm{w}} \geqq \sim 6$ earthquakes. Using subpixel correlation of historic (KH9) and recent (Sentinel-2) optical satellite images, we measure for the first time the surface displacement field of the $1979 M_{\mathrm{w}} 7.1$ Khuli-Boniabad earthquake, which broke the eastern part of the Dasht-e-Bayaz fault. Using subpixel correlation of optical (SPOT2-4) and SAR (JERS-2) images, we also measure the surface displacement field of the $M_{\mathrm{w}} 7.2$ Zirkuh earthquake, which ruptured the Abiz fault. We found that both earthquakes have a mean slip of $2.5 \mathrm{~m}$ but the Khuli-Boniabad earthquake broke two main segments (total rupture $\sim 60$ $\mathrm{km}$ ), whereas the Zirkuh earthquake broke three main segments (total rupture $\sim 125 \mathrm{~km}$ ). We suggest that the differences are controlled by the maturity of the faults, the Dasht-e-Bayaz fault being less mature than the Abiz fault. Furthermore, we succeed to measure offsets up to $2.60 \mathrm{~m}$ for the $1979 M_{\mathrm{w}} 6.6$ Korizan earthquake that broke the northern part of the Abiz fault. It is the first time that the surface displacement field for such a small historic earthquake has been measured using optical correlation. Finally, our study confirms the potential of historical optical imagery for retrieving surface displacements for past earthquakes (pre-modern geodesy era).
\end{abstract}

Key words: Satellite geodesy; Seismic cycle; Asia; Image processing; Earthquake source observations.

\section{INTRODUCTION}

It has long been thought that large earthquakes $\left(M_{\mathrm{w}}>6\right)$ were separated by a long period of interseismic quiescence in which stresses, relaxed by a preceding earthquake, were restored under the constant tectonic loading. However, an increasing number of observations indicates that large earthquakes occur in temporal clusters within fault systems (e.g. Stein et al. 1997; Pollitz et al. 2003; Sieh et al. 2008; Schlagenhauf et al. 2011; Michele et al. 2016) suggesting that additional processes are involved in the build-up and relaxation of crustal stresses. The static and post-seismic stress transfers are thought to play an important role in the spatial and temporal occurrence of such seismic sequences (see Freed 2005, for a comprehensive review). Therefore, it is crucial to understand the spatio-temporal evolution of crustal stresses to more accurately assess seismic hazard. While measuring the crustal stresses at depth currently remains out of reach, modern spatial geodetic techniques (e.g. GPS, InSAR) enable an estimation of lithospheric strain from its expression at the Earth's surface. However, to understand the behaviour of fault systems throughout a seismic cycle (lasting as long as several 10-1000 yr) requires geodetic measurements over similar timescales. It is thus necessary to extend the temporal range of geodetic observation to document the longest possible period of a seismic sequence in order to obtain a comprehensive overview of the surface displacements induced by the sequence. Optical image correlation technique (Michel \& Avouac 2002), which allows 


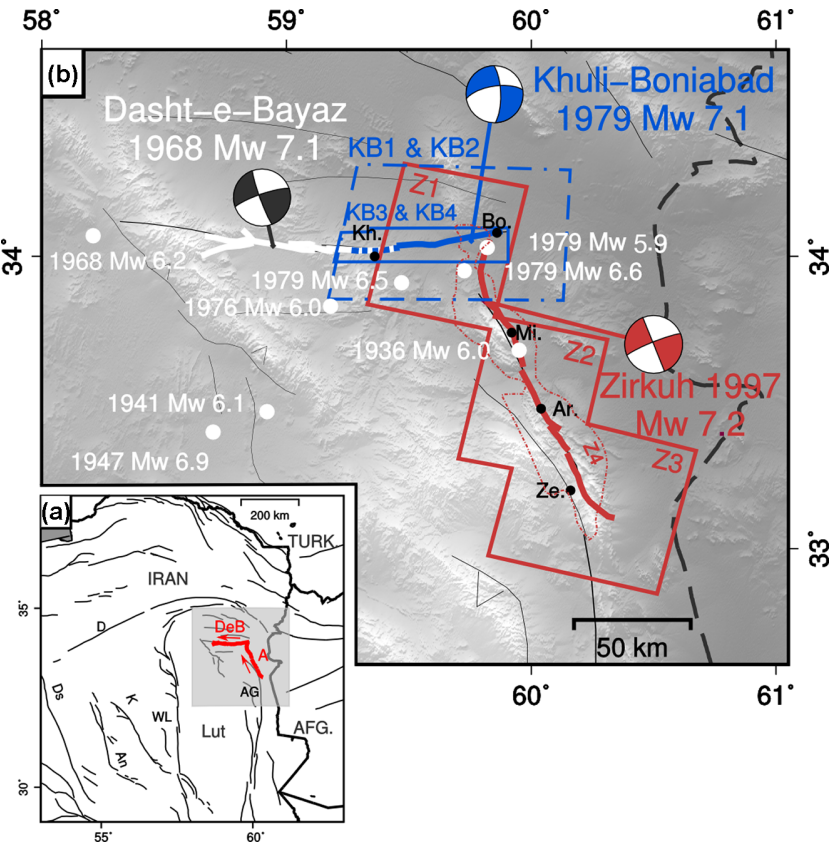

Figure 1. Regional tectonic overview. (a) Map of eastern Iran, bordering Turkmenistan (TURK) and Afghanistan (AFG), showing the main tectonic faults (thin black lines), the Abiz and Dasht-e-Bayaz faults (red thick lines) and the coverage of the study area in (b) (light grey box). Ds, An, K, D, WL, DeB, A and AG mean Deshir, Anar, Kuhbanan, Doruneh, West Lut, Dasht-e-Bayaz, Abiz and Avaz-Gazik faults, respectively. Fault mapping is from Walpersdorf et al. (2014). (b) Topographic map of northeastern Iran showing the surface rupture trace of the three $M_{\mathrm{w}}+7$ earthquakes of the sequence. The surface rupture traces of the Dasht-e-Bayaz, Khuli-Boniabad and Zirkuh earthquakes are plotted in white, blue and red, respectively. The surface ruptures of the Dasht-e-Bayaz and the Khuli-Boniabad earthquakes overlap near Khuli (dashed blue line). Focal mechanisms of the $M_{\mathrm{w}}+7$ earthquakes are represented (Engdahl et al. 2006) and white dots locate the other $M_{\mathrm{W}}+5.9$ earthquakes of the sequence (Ambraseys \& Melville 1982; Berberian \& Yeats 1999; Walker et al. 2011). The Z1, Z2, Z3 red boxes represent the coverage of optical surface displacement data of the Zirkuh earthquake, the Z4 red-dotted area is the coverage of SAR displacement data, the two blue boxes represent the coverage of the optical surface displacement data of the Khuli-Boniabad earthquake (KB1, KB2, KB3 \& KB4). Kh., Bo., Mi., Ar. and Ze. locate the cities of Khuli, Boniabad, Mirabad, Ardekul and Zeydan, respectively.

the measurement of earthquake surface displacements using crosscorrelation of optical imagery, turns out to be a powerful candidate for extending the observation time window. Actually, recent studies (Hollingsworth et al. 2012, 2013; Zhou et al. 2016) show that historical optical imagery, such as declassified U.S. spy Hexagon Keyhole-9 images (hereafter referred as KH9) can now be used to measure ground displacements resulting from large earthquakes occurring before the era of modern satellite geodesy (i.e. during the 1970s and 1980s).

In this framework, the objective of this paper is to document as best as possible the Northeast Lut (Iran) earthquake sequence. We choose this sequence that occurred on a conjugate strike-slip fault system for three reasons. First, it includes three earthquakes of $M_{\mathrm{w}} 7+$ : the $1968 M_{\mathrm{w}} 7.1$ Dasht-e-Bayaz, the $1979 M_{\mathrm{w}} 7.1$ KhuliBoniabad and the $1997 M_{\mathrm{w}} 7.2$ Zirkuh earthquakes (Fig. 1). Secondly, little is known about the surface deformation induced by these major 20th century continental earthquakes because they took place in a remote region of Iran, difficult to access, and at significant distance from seismological stations at the time of each earthquake. Thirdly, due to the geometrical configuration of the system, earthquakes here are not likely to trigger each other by static stress transfers but their occurrence in a short period of time (about $30 \mathrm{yr}$ ) is not likely to be coincidental. Therefore, the sequence is of major interest for understanding the physical controls on successive earthquake ruptures. Observation of the deformation over the sequence is thus the first step towards this overall objective.

To reach our goal to estimate the surface displacements induced by the earthquakes of the NE Lut sequence, we combine several existing remote sensing techniques (e.g. optical subpixel correlation, SAR subpixel correlation and InSAR), using notably old optical images taken in the $60 \mathrm{~s}$ and 70 s to map the displacements due to Dasht-e-Bayaz and Khuli-Boniabad earthquakes. Unfortunately, poor image quality coupled with scanning of the hardcopies (rather than negatives) prevented us from successfully correlating historic aerial photos with recent satellite images for the $1968 M_{\mathrm{w}}$ 7.1 Dasht-e-Bayaz earthquake. However, we managed to measure surface displacements for the $1979 M_{\mathrm{w}} 7.1 \mathrm{Khuli}-$ Boniabad, the $1979 M_{\mathrm{w}} 6.6$ Korizan and the $1997 M_{\mathrm{w}} 7.2$ Zirkuh earthquakes. In the following sections, we first summarize the seismic sequence, particularly the $M_{\mathrm{w}} 7.1$ Khuli-Boniabad and $M_{\mathrm{w}} 7.2$ Zirkuh earthquakes. Then we describe the method used to retrieve the surface displacement field for each earthquake. Finally, after presenting the results, we compare the surface traces and offsets for each rupture determined from the surface displacement field analysis, Pléiades optical image analysis, and published field investigations. Then we discuss the extension and propagation of the ruptures in relation to the segmentation of the faults and how fault maturity may control the obtained surface displacement patterns. Finally, we discuss the seismic hazard for the northeastern part of the Lut region.

\section{THE NORTHEAST LUT EARTHQUAKE SEQUENCE}

The 1936-1997 Northeast Lut earthquake sequence took place in northeastern Iran, mainly on the conjugate east-west left-lateral Dasht-e-Bayaz and north-south right-lateral Abiz strike-slip faults which border the Northeast Lut (Fig. 1). These faults are part of a larger north-south (NS) right-lateral and east-west (EW) left-lateral fault system that contributes to the accommodation of ArabiaEurasia convergence (Berberian et al. 1999; Vernant et al. 2004; Walker et al. 2011; Walpersdorf et al. 2014). After two centuries of quiescence in this area, eleven events of $M_{\mathrm{w}}>\sim 6$ broke the Dasht-e-Bayaz and Abiz faults and other smaller surrounding faults between 1936 and 1997 (Berberian \& Yeats 1999; Berberian et al. 1999; Walker et al. 2011; Fig. 1b). Three of the 11 events were $M_{\mathrm{w}}$ > 7 earthquakes: the $1968 M_{\mathrm{w}} 7.1$ Dasht-e-Bayaz earthquake (e.g. Ambraseys \& Tchalenko 1969), the $1979 M_{\mathrm{w}} 7.1 \mathrm{Khuli}-\mathrm{Boniabad}$ earthquake (e.g. Nowroozi \& Mohajer-Ashjai 1980), and the 1997 $M_{\mathrm{w}} 7.2$ Zirkuh earthquake (Berberian et al. 1999). These three earthquakes have almost pure strike-slip focal mechanisms with a small reverse component (Engdahl et al. 2006; Fig. 1b). The Dashte-Bayaz and Khuli-Boniabad left-lateral earthquakes broke the east and west sections of the 150-km-long Dasht-e-Bayaz fault system, respectively, whereas the right-lateral Zirkuh earthquake broke the entire 125-km-long Abiz fault (Fig. 1b). 


\subsection{The $1979 M_{\mathrm{w}} 7.1 \mathrm{Khuli}-B o n i a b a d$ earthquake and 1979 earthquake sequence}

Within 3 weeks, three main earthquakes occurred on the Dashe-Bayaz-Abiz fault connection area. It began with the $M_{\mathrm{w}} 6.6$ Korizan earthquake, on the 1979 November 14, that broke a 20 $\mathrm{km}$ section of the northern part of the Abiz fault (Haghipour \& Amidi 1980; Nowroozi \& Mohajer-Ashjai 1980; Berberian \& Yeats 1999). This was followed a week later (1979 November 27) by the larger $M_{\mathrm{w}} 7.1$ Khuli-Boniabad earthquake, which broke the eastern $65 \mathrm{~km}$ section of the Dasht-e-Bayaz fault (Haghipour \& Amidi 1980; Nowroozi \& Mohajer-Ashjai 1980). Two weeks later (1979 December 7), the $M_{\mathrm{w}} 5.9$ Kalat-e-Shur earthquake occurred (Berberian \& Yeats 1999).

This sequence, which killed a few hundred people, occurred at a time of political instability in Iran, thus hindering any extensive field investigations shortly after each event (Berberian \& Yeats 1999). This lack of direct observations leads to some debates that can impact the sequence understanding. For instance, the rupture of the northern $15 \mathrm{~km}$ section of the Abiz fault is still not linked without any doubt to one of the earthquakes of the 1979 sequence. All authors agreed that this rupture has not been produced by the Korizan earthquake but after this earthquake. Haghipour \& Amidi (1980) and Nowroozi \& Mohajer-Ashjai (1980) proposed it was produced by the Khuli-Boniabad earthquake whereas Berberian \& Yeats (1999) and Berberian et al. (1999) by the Kalat-e-Shur earthquake. On the other hand, Walker et al. (2011) relocated the Kalate-Shur earthquake further north and suggest that this earthquake could not be responsible of the northern Abiz rupture. The field investigations having been done after the Kalat-e-Shur earthquake (Walker et al. 2011), solving this issue is unlikely.

Concerning the Khuli-Boniabad earthquake rupture, two brief and possibly contradictory, field investigation reports document some of the main features observed at surface. According to Haghipour \& Amidi (1980), the Khuli-Boniabad earthquake produced a left-lateral surface rupture, with up to $4 \mathrm{~m}$ lateral slip and a maximum of $2.5 \mathrm{~m}$ vertical slip (up to the south). Nowroozi \& Mohajer-Ashjai (1980) estimated the maximum left-lateral fault offset to be $2.5 \mathrm{~m}$, with a maximum vertical fault offset of $3.8 \mathrm{~m}$, at a location near Khuli in the western part of the rupture (Fig. 1b). Surface displacement measurements from optical image correlation will allow us to better document the spatial pattern of fault slip produced by this earthquake.

\subsection{The $1997 M_{\mathrm{w}} 7.2$ Zirkuh earthquake}

On the 1997 May 10, the $M_{\mathrm{w}} 7.2$ Zirkuh earthquake broke the entire length of the Abiz fault (about $125 \mathrm{~km}$ ). Field investigations conducted after the earthquake (Berberian et al. 1999) revealed a strongly segmented fault trace with simple or overlapping steps. The most significant step-over zone is at least $800 \mathrm{~m}$ wide, and is located near Ardekul, at the junction between two segments of the Abiz fault: the northern segment runs through alluvium, while the southern segment runs through bedrock forming the mountain range (Fig. 1b). The magnitudes of the coseismic horizontal fault offsets are typically between 80 and $140 \mathrm{~cm}$ with a maximum of $\sim 230 \mathrm{~cm}$ near the southern end of the rupture. In addition, significant vertical fault offsets (up to $90 \mathrm{~cm}$ ) were observed in the southernmost part of the rupture (Berberian et al. 1999).

The rupture complexity is also highlighted by the analysis of the teleseismically recorded body-waveforms performed by Berberian et al. (1999). They showed that the $P$ and $S H$ body-waves are well fit with four subevents occurring sequentially from north to south, with relevant changes in the orientation of faulting. Subevent mechanisms vary from almost pure right-lateral strike-slip in the north and central part of the rupture to pure reverse in the southern end of the rupture.

Sudhaus \& Jonsson (2011) processed four ERS and JERS-1 coseismic interferograms from which they determined the first multisegmented fault model of the earthquake that shows the rupture segmentation and three major slip patches in good agreement with the results of Berberian et al. (1999). With a joint inversion of the InSAR and optical data, Marchandon et al. (2018) found a rougher fault model and slip distribution. In particular, changes in fault dip along the rupture are enhanced and in good agreement with the surface rupture complexity mapped from the field experiment (Berberian et al. 1999).

Although both field-based and remote-based (i.e. InSAR) measurements of ground deformation are complementary data sets and allow a good representation of the displacement field, they both have limitations when it comes to comprehensively mapping the fault rupture. InSAR can provide spatially very dense $(\sim 15 \mathrm{~m}$ resolution) and precise $(\mathrm{mm})$ measurements. However, InSAR often cannot provide measurements of the near-field of fault zones $(<\sim 10$ $\mathrm{km}$ from the rupture) due to a lack of coherence in areas of high strain gradient. Furthermore, the line-of-sight (LOS) component of the surface displacements is not always optimally oriented with respect to the coseismic slip (e.g. InSAR cannot resolve ground displacements in the along-track direction of the satellite). On the other hand, field measurements of fault displacement are generally sparse and often do not capture the component of deformation occurring off the main fault, either as minor localized slip on secondary structures or as purely distributed deformation . Therefore, additional surface offset measurements from optical image correlation, which better captures displacements in the near-field, will complement both InSAR and field measurements, thus providing a more complete picture of the surface displacement field generated by this event.

\section{DATA AND METHODS}

\subsection{Subpixel correlation of SPOT, Sentinel and KH9 optical satellite images}

Optical image correlation retrieves the horizontal surface displacement field produced by an earthquake by measuring subpixel shifts (detection threshold: $\sim 10$ percent of the image pixel resolution) between two coregistered and orthorectified optical satellite images acquired before and after the event (Leprince et al. 2007). This technique has been successfully used to investigate near-field surface displacements produced by recent earthquakes (e.g. Konca et al. 2010; Copley et al. 2012; Wei et al. 2011; Milliner et al. 2015; Vallage et al. 2015; Hollingsworth et al. 2017; Kääb et al. 2017). In this study, all the methodological steps needed to derive surface displacement maps from raw pre- and post-earthquake optical images are made using the COSI-Corr software package (Leprince et al. 2007) following the methodology described in the software user guide (Ayoub et al. 2015).

The first processing step uses tie points to align both pre- and post-earthquake images, which are then brought into a common viewing geometry via the orthorectification process. This consists of resampling both images, while accounting for topography and any off-nadir obliquity in the satellite viewing angle, to produce an 
image with a regular horizontal ground sampling; thus achieving a viewing geometry equivalent to images acquired at nadir. In this study, the post-earthquake image is orthorectified using the image metadata (orbit and attitude of the satellite and incidence angles for each pixel), a digital elevation model (DEM) of the studied area, and a shaded version of this DEM as a reference image used to align the post-earthquake image with the topography. The pre-earthquake image is then coregistered to the post-earthquake orthoimage using tie points, and then orthorectified using the supplied metadata and the DEM. Once both pre- and post-images are orthorectified, we correlate them using a Fourier-based frequency correlator with a multiscale sliding correlation window of 128 to 64 pixels (Ayoub et al. 2015) and a measurement step size of 8 pixels (Leprince et al. 2007). We thus obtain the north-south and east-west surface displacement field of the earthquake. Finally, the surface displacement fields are denoized by removing outliers and points with a low signal-to-noise ratio $(<0.97)$, and the high frequency noise of the three surface displacement maps is reduced using the non-local mean filter implemented in COSI-Corr (Buades et al. 2008). For the non-local mean filter, we used a patch size of $5 \times 5$ pixels, an area dimension of $21 \times 21$ pixels and a noise parameter value between 0.4 and 0.8 (Ayoub et al. 2015). In this paper, we use both modern pushbroom optical satellite images (SPOT 2-4, Sentinel-2) acquired between 1991 and 2017, and older film-based satellite photos (KH9) acquired in 1976 to measure the surface displacement field of the Khuli-Boniabad and Zirkuh earthquakes. Table 1 summarizes the metadata of the images we used, Table 2 gives the characteristics of the calculated correlation, and Fig. 1 shows the satellite data footprints.

We compute the horizontal surface displacement field of the Zirkuh earthquake using subpixel correlation of three pairs of SPOT images of $10 \mathrm{~m}$ resolution (Z1, Z2 and Z3, Fig. 1). The three surface displacement maps contained striping artefacts resulting from misalignment of the CCD (Charged Coupled Devices) arrays on the satellite sensor (Leprince et al. 2007); such artefacts were removed using the destriping tool in COSI-Corr (Ayoub et al. 2015). The only available optical images pre-dating the 1979 Khuli-Boniabad earthquake are declassified satellite photos from the U.S. KH9 spy satellite. The KH9 negatives are scanned by the USGS at $7-\mu \mathrm{m}$ (3600 dpi) using a high performance photogrammetric film scanner and the digital copies can be purchased from the USGS Earth Explorer website for $\$ 30$. We use a stereo pair of KH9 images acquired in 1976 (Table 1). Although the metadata of KH9 images are not declassified, Surazakov \& Aizen (2010) have demonstrated that the focal length of the KH9 camera was $30.5 \mathrm{~cm}$ and that KH9 images are equivalent to very high altitude aerial photos for the orthorectification process. We use this information, along with the grid of calibration points spaced every $1 \mathrm{~cm} \times 1 \mathrm{~cm}$ across the image (originally used to correct for distortion), to define the intrinsic camera geometry (Interior orientation file of COSI-Corr) required for orthorectification. For the post-earthquake image, we use a Sentinel-2 image from 2017 (10 m resolution) freely available from the European Space Agency (https://scihub.copernicus.eu/dhus/\#/home). To limit illumination bias in the correlations, we use Sentinel-2 images acquired at the same point in the season (i.e. January) as for the KH9 images (Hollingsworth et al. 2017). As Sentinel-2 images are delivered as an orthorectified product, we simply coregister and orthorectify the KH9 images using the Sentinel-2 image as the reference image and a DEM of the studied area.

In a first test, we orthorectify the KH9 images with the worldwide $30 \mathrm{~m}$ SRTM DEM and correlate the orthorectified KH-9 images with the Sentinel-2 image (KB1 and KB2 displacement fields,
(Tables 1 and 2, Fig. 1b). Because the KH9 images are acquired with a frame camera, the incidence angle varies radially outwards from the optical centre. Therefore, when KH9 images are orthorectified using a DEM of lower resolution than the original KH9 image (e.g. 30 and 6-9 m, respectively), residual topographic information will remain in the images, becoming stronger towards the edges. These uncorrected topographic features will therefore be retrieved during the correlation process, resulting in significant topographically correlated noise in the KB1 and KB2 displacement fields (Fig. S1b in supporting information). To minimize this problem, we use $0.5 \mathrm{~m}$ resolution tri-stereo Pléaides images from 2015 to extract a $2 \mathrm{~m}$ resolution DEM for the area using the open-source Ames Stereo Pipeline software package (Shean et al. 2016). We use this highresolution Pléaides DEM to orthorectify the KH9 images, which we then correlate with the Sentinel-2 images from 2017. We obtain the KB3 and KB4 displacement fields (Tables 1 and 2, Fig. 1b and Figs $\mathrm{S} 2-\mathrm{S} 3$ in supporting information). The Pléaides DEM covers only the Dasht-e-Bayaz fault, so the KB3 and KB4 footprints are smaller than the KB1 and KB2 footprints (Fig. 1b). We remove a very long wavelength trend from both components of the four displacement fields (KB1-KB4) by subtracting a second order polynomial using the detrending tool of COSI-Corr (see the example of the KB2 EW displacement field in Fig. S1). Such distortions are commonly seen when correlating film-based images and are usually due to thermomechanical warping of the photographic film (Michel \& Avouac 2006; Ayoub et al. 2009; Hollingsworth et al. 2012; Milliner et al. 2015). Nevertheless, distortions typically have a much greater wavelength than the coseismic step, and so their removal does not bias the near-field coseismic offset measurement. Finally, we average the $\mathrm{KB} 3$ and KB4 displacement fields to increase the signal-to-noise ratio. We then use the $\mathrm{KB} 3 / \mathrm{KB} 4$ average displacement field to study the Khuli-Boniabad earthquake (Fig. 2). In addition, we also use the KB2 displacement field, due to its wider ground coverage, to investigate the northern part of the Abiz fault between 1979 and 2017 (Tables 1 and 2).

\subsection{Subpixel correlation of SAR images}

We also use the subpixel correlation technique to measure pixel offsets between of pre- and post-Zirkuh earthquake JERS-1 SAR amplitude images ( L-band, $\lambda=0.23 \mathrm{~m}$ ) using the GAMMA software (Wegmüller \& Werner 1997). The images were acquired on 1994 November 15 and 1997 July 10. We calculated only the pixel offsets in the azimuth direction of the SAR acquisitions, which give a N12 horizontal surface displacement field of the Zirkuh earthquake. The precision of SAR amplitude image pixel tracking is similar to optical correlation (i.e. 10 percent of the input pixel resolution, that is $4.5 \mathrm{~m}$ pixel size in the azimuth direction). We correlate subwindows within the images with a size of 128 by 128 pixels and use a step size of 128 pixels, such that each pixel offset measurement is independent of the neighbouring one.

\section{RESULTS}

\subsection{The $1979 M w 7.1$ Khuli-Boniabad earthquake}

Fig. 2 shows the EW and NS surface displacement fields for the Khuli-Boniabad earthquake obtained from the average of the KB3 and KB4 surface displacement fields (Table 2). On the EW surface displacement field (Fig. 2a), we can clearly see the EW trending left-lateral rupture trace of the Khuli-Boniabad earthquake. The 
Table 1. Optical satellite image meta-data.

\begin{tabular}{|c|c|c|c|c|c|}
\hline $\begin{array}{l}\text { Displacement } \\
\text { map }\end{array}$ & Sensor & $\begin{array}{c}\text { Spatial } \\
\text { resolution (m) }\end{array}$ & $\begin{array}{c}\text { Date } \\
\text { (year-month-day) }\end{array}$ & $\begin{array}{l}\text { Time span } \\
(\mathrm{yr})\end{array}$ & $\begin{array}{c}\text { Incidence angle } \\
\left({ }^{\circ}\right)\end{array}$ \\
\hline \multirow[t]{2}{*}{$\mathrm{Z1}$} & SPOT 2 & 10 & $91-08-27$ & 14.3 & -0.5 \\
\hline & SPOT 2 & 10 & 05-09-04 & & -1 \\
\hline $\mathrm{Z} 2$ & SPOT 4 & 10 & 00-06-02 & & 2.9 \\
\hline \multirow[t]{2}{*}{$\mathrm{Z3}$} & SPOT 3 & 10 & $95-10-05$ & 6.42 & 25.8 \\
\hline & SPOT 4 & 10 & 02-03-08 & & 26.1 \\
\hline \multirow[t]{2}{*}{$\mathrm{KB} 2 / \mathrm{KB} 4$} & KH9 - 5001 & $6-9$ & 76-01-09 & 41 & Radial \\
\hline & Sentinel-2 & 10 & $17-01-11$ & & Orthorectified \\
\hline
\end{tabular}

Table 2. Specifications for optical image correlations and pixel offsets.

\begin{tabular}{|c|c|c|c|c|}
\hline $\begin{array}{l}\text { Displacement } \\
\text { map }\end{array}$ & $\begin{array}{l}\text { DEM used for the } \\
\text { orthorectification process }\end{array}$ & $\begin{array}{l}\text { Correlation window } \\
\text { size (pixels) }\end{array}$ & $\begin{array}{l}\text { Correlation window } \\
\text { step size (pixels) }\end{array}$ & $\begin{array}{l}\text { Accepted offset } \\
\text { range } d(m)\end{array}$ \\
\hline $\mathrm{Z1}$ & ASTER GDEM (30 m) & 128 to 64 & 8 & $-5 \mathrm{~m}<\mathrm{d}<5 \mathrm{~m}$ \\
\hline $\mathrm{Z} 2$ & ASTER GDEM (30 m) & 128 to 64 & 8 & $-5 \mathrm{~m}<\mathrm{d}<5 \mathrm{~m}$ \\
\hline KB1 & SRTM $(30 \mathrm{~m})$ & 128 to 64 & 8 & $-10 \mathrm{~m}<\mathrm{d}<10 \mathrm{~m}$ \\
\hline KB2 & SRTM (30 m) & 128 to 64 & 8 & $-10 \mathrm{~m}<\mathrm{d}<10 \mathrm{~m}$ \\
\hline KB3 & Pléaides (2 m) & 128 to 64 & 8 & $-10 \mathrm{~m}<\mathrm{d}<10 \mathrm{~m}$ \\
\hline
\end{tabular}

detectable rupture trace is $\sim 50 \mathrm{~km}$ long and bends dramatically at its western end. From east to west, the rupture strike is $\mathrm{N} 65^{\circ}$ from points $\mathrm{A}$ to $\mathrm{B}(\sim 10 \mathrm{~km})$. Then the fault bends and the rupture strike becomes $\mathrm{N} 85^{\circ}$ until point $\mathrm{C}(\sim 7.5 \mathrm{~km})$. At point $\mathrm{C}$, the fault exhibits a double bend and the fault strike changes sightly to $\mathrm{N} 81^{\circ}$ for about $6.6 \mathrm{~km}$ (until point $\mathrm{D}$ ). Between points $\mathrm{D}$ and $\mathrm{F}$ the surface fault trace is unclear $(\sim 20 \mathrm{~km})$. Finally, the fault trace bends abruptly west of point $\mathrm{F}$ and the strike becomes $\mathrm{N} 160^{\circ}$ for $\sim 6 \mathrm{~km}$. Figs 2 (c) and (d) show two examples of fault-perpendicular profiles (see Fig. 2a for profile locations). Profile P1 (Fig. 2c) shows an offset across the fault of $\sim 4.92 \pm 0.73 \mathrm{~m}$; this value is typical of the fault offsets west of point E. The large error of the measured offset, as well as the high standard deviation of the stacked profile is representative of the high level of noise on this part of the fault. Profile P2 (Fig. 2d) shows an offset across the fault of $\sim 2.24 \pm 0.26 \mathrm{~m}$, this value is representative of the fault offset between points A and C. Contrary to the western end of the rupture, the surface displacement for this part of the rupture is quite clean, as highlighted by the low offset error and the low standard deviation of the stacked profile. In order to further investigate the along-strike variation of the fault offsets, 12 other profiles oriented perpendicular to the fault strike have been computed. The curve of the along-strike offset variation will be presented and discussed along with the field offset measurements (Nowroozi \& Mohajer-Ashjai 1980) in Section 5.1.1.

On the NS displacement field, a discontinuity trending $\sim \mathrm{N} 100^{\circ} \mathrm{E}$ is visible near longitude $59^{\circ} 42^{\prime} \mathrm{E}$. Given the orientation of this segment, this signal could involve $\sim \mathrm{N} 10^{\circ} \mathrm{E}$ shortening. This segment could be attributed to a mapped fault but no $M_{\mathrm{w}} \geq 5$ earthquakes occurred on or in the immediate vicinity of this fault between 1976 and 2017 (Walker et al. 2011). Additionally, it is unlikely that the EW left-lateral strike-slip Khuli-Boniabad earthquake produced NS shortening on a $100^{\circ} \mathrm{E}$ fault. Finally, several sources of noise could explain this signal. There is a river flowing along this segment that could bias the signal. Moreover, in this area, the NS surface displacement field is correlated with topography. It is likely the result of the epipolar plane, which contains the majority of the stereo signal, aligning closely to the NS direction. Thus, we are rather confident that this $\mathrm{N} 100^{\circ}$ discontinuity is not a tectonic signal. Concerning the Khuli-Boniabad rupture, the NS surface displacement field is expected to be low due to the EW strike-slip mechanism of the rupture. However, close to both ends of the rupture, detectable NS displacements also highlight the fault trace (Fig. 2b). Unfortunately, the NS offsets are not sufficiently clear to be measured.

\subsection{The $1997 M_{\mathrm{w}}$ 7.2 Zirkuh earthquake}

\subsubsection{NS and EW displacement fields of the Zirkuh earthquake}

Fig. 3 a displays the NS surface displacement field of the 1997 $M_{\mathrm{w}} 7.2$ Zirkuh earthquake obtained from SPOT image correlation. The surface displacement field shows many decorrelation areas due to the surface changes that occurred during the $\sim 10$ yr separating the pre- and post-images. Most of these surface changes occurred in alluviums and deposit areas or are man-made modifications in cities or agricultural zones.

Despite the noise due to temporal decorrelation, the NNW-SSE rupture trace can be well mapped. According to the clearness of the surface rupture trace, we divide the fault in five sections. On three sections of the fault, the surface rupture trace is unambiguously identifiable thanks to clear steps in the surface displacement field across the fault. We name these sections the Korizan section (north of latitude $33.80^{\circ}$ ), the Bashiran section (between latitude $33.5^{\circ}$ and $39.65^{\circ}$ ) and the Zeydan section (south of latitude $33.36^{\circ}$; Fig. 3a). In between these three zones, in the Ardekul and Mirabad sections, the surface trace of the rupture is less clear (Fig. 3a). In the Ardekul section, surface displacements change only very gradually across the fault (Fig. 3c, profile DD'). In the Mirabad section, the fault trace seems to be more complex and composed of two fault branches, an eastern and a western fault branch, which could connect to the two fault branches clearly identifiable in the southern part of the Korizan section (Fig. 3b). 

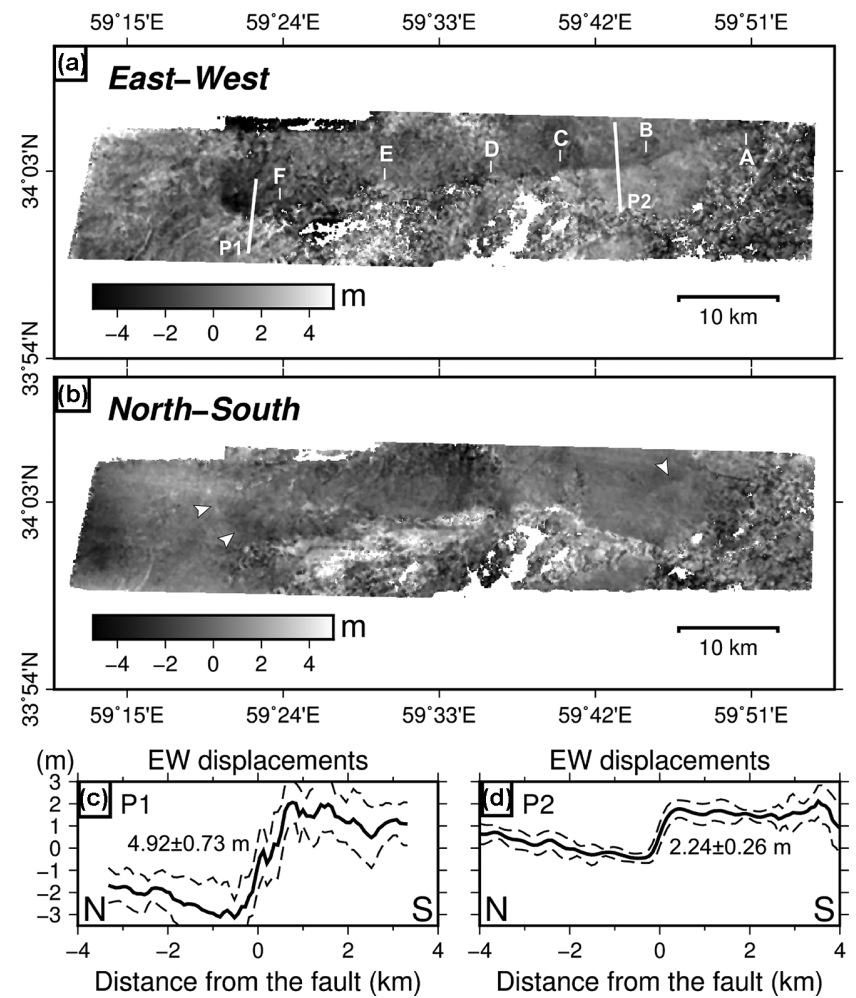

Figure 2. Khuli-Boniabad earthquake surface displacement fields from the correlation of KH9 and Sentinel-2 images (average of KB3 and KB4 displacement fields, Table 2) over the source region of the 1979 Khuli-Boniabad earthquake. (a) Eastwest displacement field. The white lines are the location of the profiles on (c and d). (b) North-south displacement field. The white arrows mark the fault trace. Displacement is positive for northward and eastward motions. (c and d) Fault-perpendicular profiles. The thick black line is the stack of 51 profiles on a 4-km-wide box whereas the dashed lines represent the standard deviation of the stacked profile. The fault offsets are estimated by fitting linear regressions to the surface displacement profiles on either side of the fault and measuring the surface displacement difference of the linear regression across the fault. The error of the estimated fault offset is given by the root mean square of standard deviations of the linear regressions on each side of the fault.

Fig. 3(c) shows five fault-perpendicular profiles representative of each section of the fault (see Fig. 3a for profiles location). In the Korizan section, on profile AA', the NS offset across the fault is 2.02 $\pm 0.58 \mathrm{~m}$. In the Mirabad section, the profile BB' does not show a clear offset; a large bump is located on the western fault branch $(-4 \mathrm{~km})$ and the eastern fault branch is highlighted by an increase of noise east of $0 \mathrm{~km}$. In the Bashiran section, on profile CC', the NS displacement offset is $2.31 \pm 0.70 \mathrm{~m}$. In the Ardekul section, on profile DD', the NS displacement gradient is wide and the measured offset is very low $(0.19 \pm 0.47 \mathrm{~m})$. In the Zeydan section, the profile EE' shows an offset of $1.90 \pm 0.2 \mathrm{~m}$. The standard deviation of the stacked profiles AA', BB' and CC' is higher on the eastern part of the fault than in the western part due to phase decorrelation. Finally, the profile CC' shows a large convex signal in the eastern part of the fault due to the southward migration of several sand dunes.

Fig. 4(a) displays the EW surface displacement field of the 1997 $M_{\mathrm{w}} 7.2$ Zirkuh earthquake. The surface displacement field shows the same decorrelation areas as seen in the NS displacement field. As expected for a NNW-SSE strike-slip fault, the changes in surface displacement across the surface trace of the rupture are smaller in the EW directions (Fig. 4a). The five sections of the fault are therefore more difficult to differentiate. Indeed, offsets smaller than $\sim 1 \mathrm{~m}$ are difficult to detect given the spatial resolution of the optical images used and the high level of temporal decorrelation in the resulting displacement fields. In the Korizan section and Mirabad section, the offsets across the fault are below the noise level of the data and are thus not detectable (Profiles AA' and BB', Fig. 4b). Moreover, the profile BB' shows a peak at $-3.5 \mathrm{~km}$ located at the same place as the western fault branch in the NS displacement field (Fig. 3). On the Bashiran section, the profile CC' shows an offset of $0.70 \pm 0.57 \mathrm{~m}$. The Ardekul section still shows a low displacement gradient across the fault $(0.40 \pm 0.47 \mathrm{~m}$ on profile DD'). Finally, in the Zeydan section, the EW surface displacement field shows a topographically correlated signal on the eastern part of the fault (see also Fig. S4 in supporting information). This signal occurs due to topography that was locally changed by the earthquake and offnadir look angles $\left(25.8^{\circ}\right.$ and $26^{\circ}, \mathrm{Z} 3$ in Table 1$)$, while using only one DEM (here post-earthquake) to orthorectify both the pre- and post-earthquake images (Ayoub et al. 2009). This topographically correlated signal mostly shows in the EW component because the viewing angle of SPOT satellite can only be adjusted in the acrosstrack direction (i.e. $\sim \mathrm{E}-\mathrm{W}$ ). It can be corrected only if the vertical surface displacements can be neglected (Ayoub et al. 2009). Unfortunately, it is not the case in the southern part of the rupture, based on field measurements and InSAR data (Berberian et al. 1999; Sudhaus \& Jonsson 2011). Consequently, part of the vertical surface displacement is projected into the apparent EW surface displacement component. Therefore, the clear $1.14 \pm 0.36 \mathrm{~m}$ offset visible on the profile EE' is apparent and could include a part of the vertical displacement.

\subsection{2 $\mathrm{N} 12^{\circ}$ displacement field of the Zirkuh earthquake}

The Fig. 5 shows the horizontal surface displacement field of the Zirkuh earthquake in the $\mathrm{N} 12^{\circ}$ azimuthal direction inferred from the correlation of JERS-1 SAR amplitude images. The level of noise is higher than in the NS displacement field, although we can still clearly detect the five sections of the fault. The Korizan, Bashiran and Zeydan sections are still characterized by large surface displacement offsets across the fault (Fig. 5b), whereas the gradients of the N12 surface displacement are low in the Mirabad and Ardekul sections (Fig. 5b, BB' and DD' profiles). Indeed, the offsets of profiles AA', CC' and EE' are $1.44 \pm 0.23 \mathrm{~m}, 1.88 \pm 0.46$ and $2.32 \pm 0.55 \mathrm{~m}$, whereas they are $0.77 \pm 0.27 \mathrm{~m}$ and $0.45 \pm 0.31 \mathrm{~m}$, in profiles BB' and DD', respectively. In the Mirabad section, no observation confirms the presence of the western branch seen in the NS displacement field (Fig. 3b). This zone is characterized by a smooth gradient across the fault, similar to the Ardekul section.

\subsubsection{Constraints on the vertical displacement field of the Zirkuh earthquake}

The three displacement fields described above give constraints only on the horizontal displacement field of the Zirkuh earthquake. To give constraints on the vertical surface displacements, we use the JERS-1 SAR interferogram processed by Sudhaus \& Jonsson (2011) that encompasses the entire rupture. The InSAR technique measures the surface displacement in the LOS of the sensor, which is on average $39^{\circ}$ off the vertical for the JERS- 1 satellite. The InSAR surface displacements are thus more sensitive to the vertical component of surface displacement, as $\sim 78$ per cent of the vertical displacement is projected in the LOS component, whereas only $\sim 63$ and 


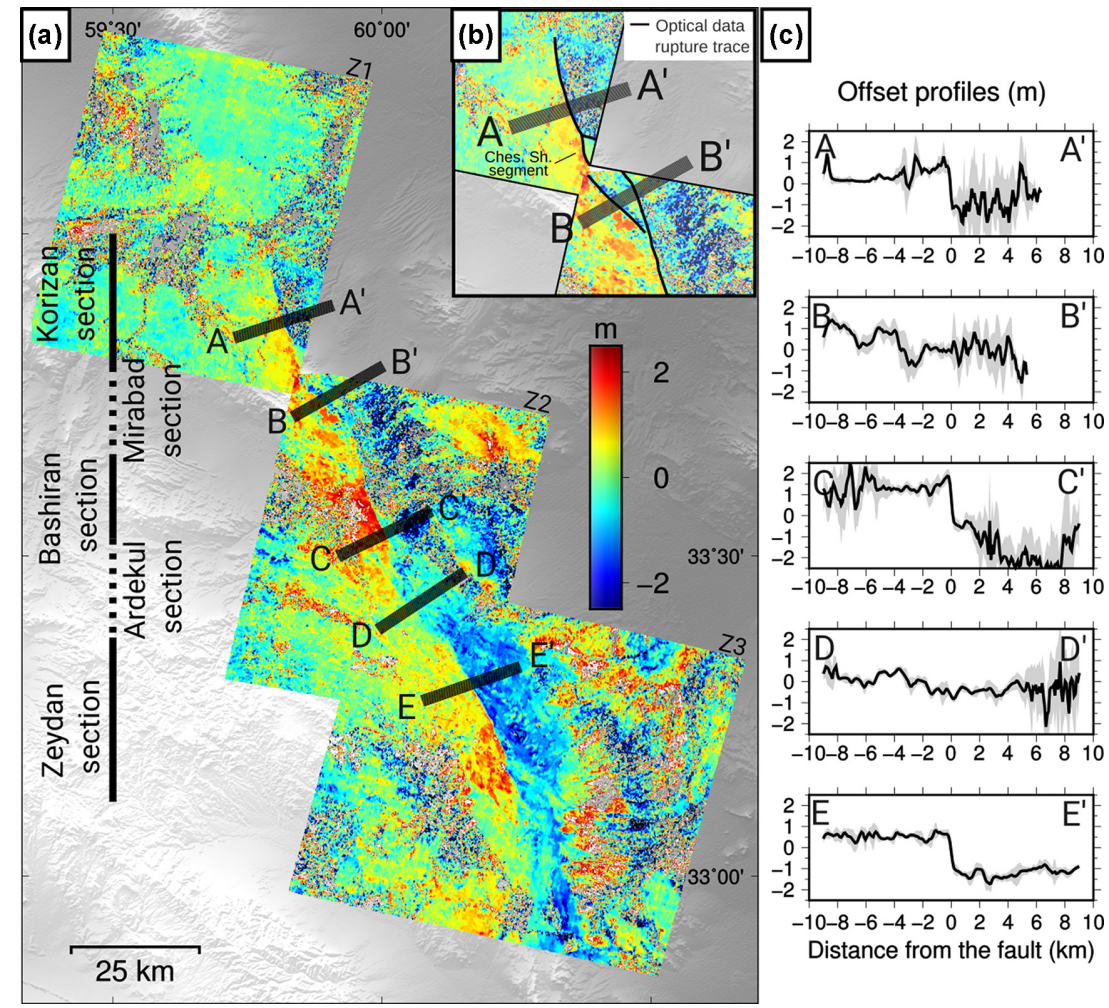

Figure 3. (a) Zirkuh earthquake north-south surface displacement field (m) from SPOT images correlation. Displacements are positive northward. The grey boxes represent the location of the profiles shown in (c). On the left of the figure, the thick black lines delimit sections of large surface displacement gradients and the dashed lines delimit sections of small surface displacement gradients across the fault. (b) Zoom on the Mirabad section. Ches. Sh. means Cheshmeh Shahtut. (c) Fault-perpendicular profiles. The thick black line is the stack of 12 profiles on a $2-k m$-wide box whereas the grey envelope represents the standard deviation of the stacked profiles.

$\sim 10$ percent of the EW and NS surface displacements are projected in the LOS component, respectively. The noise level is very low on the LOS displacement field but the interferometric phase decorrelation due to large phase gradients near the fault prevents any offset measurements in the near-field (Fig. 6). To fill the observational gap and to estimate LOS surface displacement offsets across the fault, we use the predictions of the source model estimated by Sudhaus \& Jonsson (2011; Fig. 6b). Xu et al. (2016) have shown, when inverting InSAR data to produce a fault slip model, that large data gaps near the fault can artificially give rise to shallow slip deficit in the slip model. Hence the offsets that we estimate using the source model of Sudhaus \& Jonsson (2011) could be underestimated. However, the offsets are internally consistent when taken as a whole. According to Fig. 6(b), the profiles of all sections except the Mirabad section are characterized by high slip gradient across the fault. The offsets of profiles AA', BB', CC', DD' and EE' are $0.50,0.30,0.70$ and $0.79 \mathrm{~m}$ and $1.20 \mathrm{~m}$, respectively, in the LOS direction.

\section{DISCUSSION}

\subsection{Comprehensive overview of surface displacement} fields of the Khuli-Boniabad and Zirkuh earthquakes

\subsubsection{Khuli-Boniabad earthquake}

In Fig. 7(b), we show the comparison of the surface rupture of the Khuli-Boniabad earthquake mapped from optical image correlation (Figs 2 a and 7a) with the one obtained from field investigation
(Nowroozi \& Mohajer-Ashjai 1980). We also map the trace of the fault rupture using both the $0.5 \mathrm{~m}$ Pléiades images and the $2 \mathrm{~m}$ Pléiades DEM (Figs $7 \mathrm{~b}$ and 8). While we are not able to map the entire surface rupture trace from optical correlation and highresolution Pléiades imagery, the three data sets represent the most comprehensive data set thus far.

The three surface rupture maps are broadly consistent. The western part of the rupture, from the extensive relay zone observed from field mapping (point E, Fig. 7b), is very similar from one dataset to another. In particular, they all highlight the sharp fault bend west of Khuli (west of point F, Figs $7 \mathrm{~b}$ and 8, Section 4.1 and Fig. 2). They also roughly show the same spatial extent, except in the region west of the bend, where the EW displacement field does not show any clear surface fault trace, and where the surface fault trace mapped from Pléiades imagery differs from the field mapping. However, the $1968 M_{\mathrm{w}} 7.1$ Dasht-e-Bayaz earthquake also broke this part of the fault (Ambraseys \& Tchalenko 1969). Thus, we cannot be sure that the fault trace seen in the Pléiades images is due to the KhuliBoniabad earthquake, or the earlier event. Indeed, the arid climate in this region makes the surface rupture trace well preserved. As only 11 yr separate the earthquakes, the 1979 rupture can be hard to distinguish from the 1968 one. Finally, about $10 \mathrm{~km}$ from the eastern end of the rupture and continuing for $17 \mathrm{~km}$ (up to point $\mathrm{D}$ ), rupture traces from the optical correlation data and high-resolution Pléiades data are similar, but differ from the field measurements. The field-mapped rupture trace is clearly located $\sim 2 \mathrm{~km}$ further north at point $\mathrm{B}$. For the rest of the rupture, from point $\mathrm{D}$ to $\mathrm{E}$, it 


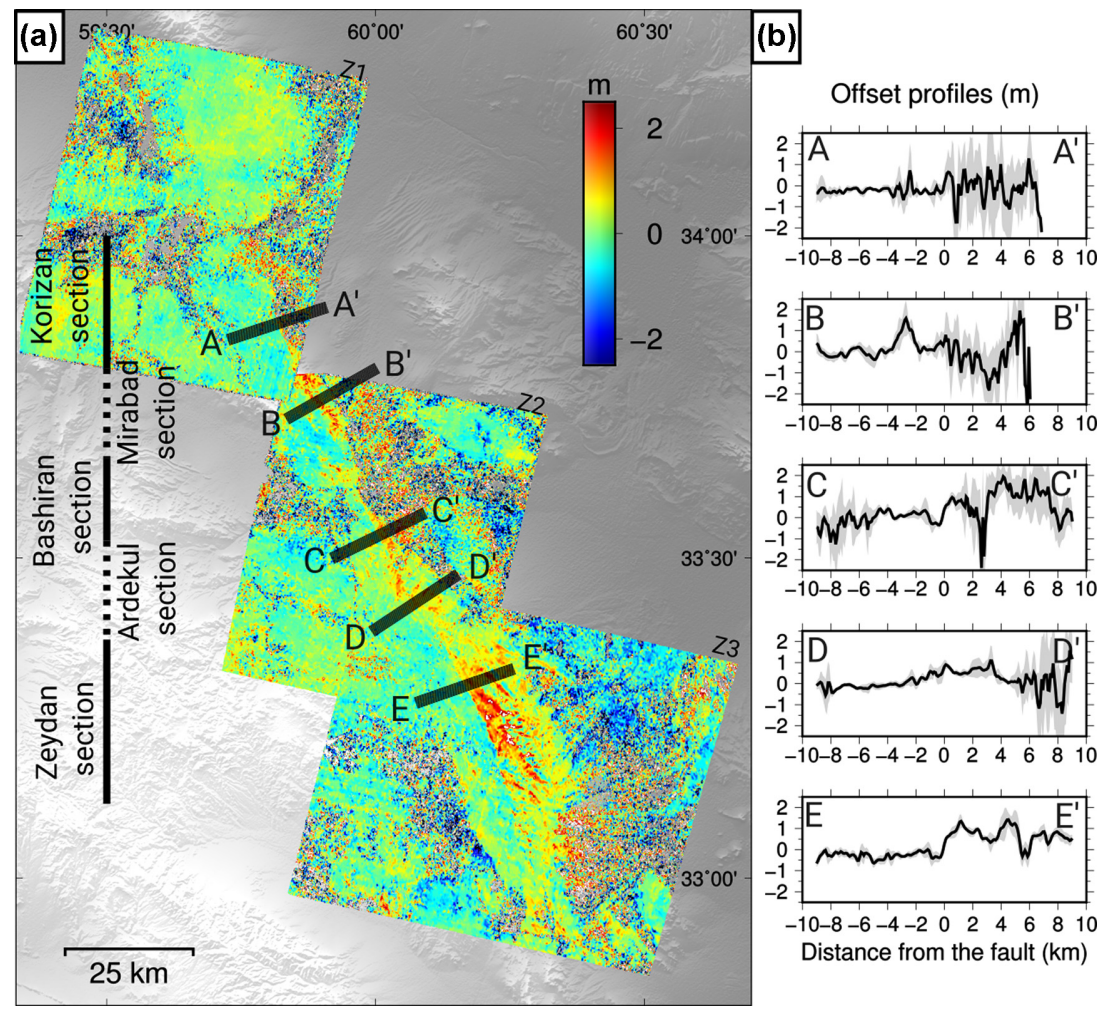

Figure 4. (a) Zirkuh earthquake east-west surface displacement field (m) from SPOT images correlation. Displacements are positive eastward. The grey boxes represent the location of the profiles shown in (b). The thick black lines delimit sections of high surface displacement gradient and the dashed lines delimit sections of low surface displacement gradient. (b) Fault-perpendicular profiles. The thick black line is the stack of 12 profiles on a 2-km-wide box whereas the grey envelope represents the standard deviation of the stacked profiles.

is difficult to resolve precisely the rupture trace both from the image correlation and the high-resolution Pléiades data, and we thus cannot meaningfully compare it to the field rupture trace.

We now compare the fault offsets (Fig. 7c) measured in the field (Nowroozi \& Mohajer-Ashjai 1980) with the ones estimated from the EW optical surface displacement data (Figs $2 \mathrm{a}$ and $7 \mathrm{a}$ ). Such a comparison is meaningful because the fault strike is east-west and the fault mechanism is mainly left-lateral strike-slip. On the eastern part of the rupture, between points A and D (about $23 \mathrm{~km}$ ), fault offsets are well described along the rupture with the optical correlation data, but only sparsely described with field measurements. On the western part of the rupture, from point $E$ to the end of the rupture (about $21 \mathrm{~km}$ ), it is roughly the contrary. Both data sets are thus very complementary. On the eastern part, the EW optical fault offsets are about $2.5 \mathrm{~m}$ with a maximum of $3 \mathrm{~m}$ near $28 \mathrm{~km}$, which decrease to $1 \mathrm{~m}$ at $25 \mathrm{~km}$. Along this part of the rupture, only two along-strike and vertical field offsets were measured. They are estimated to be less than $0.5 \mathrm{~m}$. The along-strike field offset measured at $22 \mathrm{~km}$ could be in good agreement with the EW optical offset at $25 \mathrm{~km}$. However, the field and optical offsets measured at $32 \mathrm{~km}$ are not consistent with each other. On the western and E-W striking part of the rupture (from point $\mathrm{E}$ to $\mathrm{F}$ ), the horizontal and vertical field offsets gently increase from 0.5 to $2.5 \mathrm{~m}$, whereas no reliable E-W optical offsets can be measured due to temporal decorrelation. West of point $F$, where the fault strike becomes north-south, vertical field offsets reach $4 \mathrm{~m}$ at $-2.5 \mathrm{~km}$ and both horizontal and vertical field offsets decrease abruptly to zero at $\sim-10 \mathrm{~km}$. On this part of the rupture, the EW optical offsets form a sharp curve reaching $\sim 5 \mathrm{~m}$, consistent with the field measurements. Similar offsets in both the EW and vertical suggest this 7-km-long and NS-striking fault segment is a thrust with a $\sim 45 \mathrm{E}$ dip.

Finally, the field and E-W optical offset measurements are either in good agreement either complementary almost everywhere except in the eastern part of the rupture (between points B and C). It is also where the rupture trace from field mapping does not well match the trace derived from the optical displacement data and highresolution Pléiades images (at a $\sim 2 \mathrm{~km}$ level, see Fig. $7 \mathrm{~b}$ ). We are confident in our correlation results as the surface displacement field clearly discriminates the rupture location (Fig. 7a). We therefore suggest that the main rupture trace has been missed during the field investigations, which may also explain the low offsets they measured.

If so, the combination of the field and EW optical offset curves indicates two peaks in surface slip separated by a zone of lower surface slip. The western peak ( $17 \mathrm{~km}$ length minimum) is sharp with a mainly strike-slip component on the EW striking part, and a thrust component on the NS striking part. The eastern peak $(15 \mathrm{~km}$ length minimum) appears smoother, although our data does not well describe each end. The low surface slip zone (i.e. with slip lower than $1 \mathrm{~m}$, between points $\mathrm{D}$ and $\mathrm{E}$ ) is more difficult to characterize, although its length should not exceed about $15 \mathrm{~km}$. Moreover, the fact that the rupture trace could also not be retrieved either from optical correlation data or from high resolution optical Pléiades data between 10 and $22 \mathrm{~km}$ may suggest: (1) low localized displacement, (2) distributed displacement on several fault branches, (3) higher erosion of the scarps than elsewhere, which would limit the rupture detection in the optical Pléiades data and increase the temporal decorrelation in the optical correlation data or (4) a combination of these explanations. While we still miss along-strike data, we 


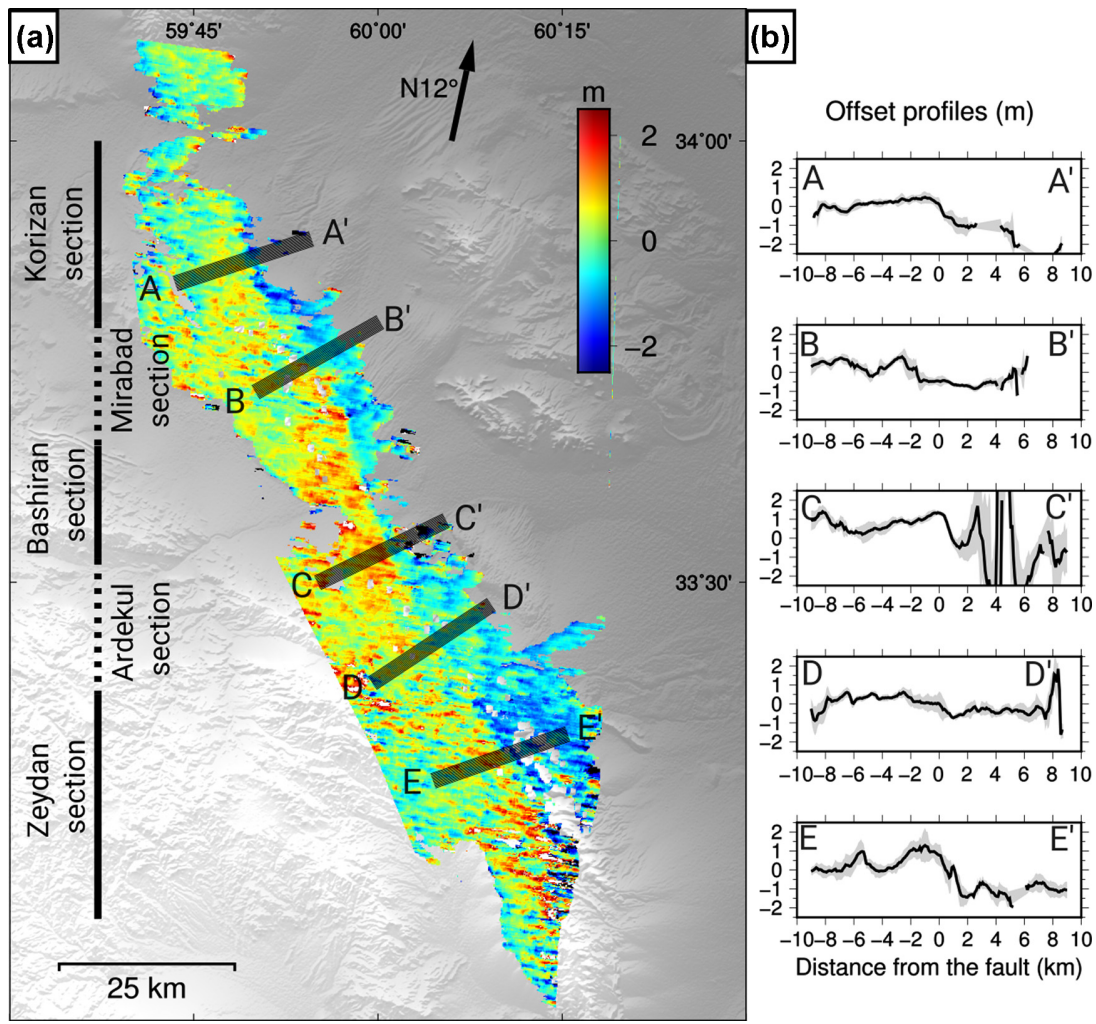

Figure 5. (a) Zirkuh earthquake $N 12^{\circ}$ surface displacement field (m) from SAR images correlation. Displacements are positive towards $N 12^{\circ}$ direction. The grey boxes represent the location of the profiles shown on (b). On the left of the figure, the thick black lines delimit section of large surface displacement gradient and the dashed line delimit the section of small surface displacement gradient (b) Fault-perpendicular profiles. The thick black line is the stack of 12 profiles on a $2 \mathrm{~km}$-wide box whereas the grey envelope represents the standard deviation of the stacked profiles.

suggest that the Khuli-Boniabad earthquake results in a rupture of two main segments separated by a low slip zone (segments S1 and S2, Fig. 7c).

The optical surface displacement field we obtain is not as precise as displacement fields obtained with more recent, or higher resolution data, with smaller temporal baselines (e.g. Milliner et al. 2015; Vallage et al. 2015; Hollingsworth et al. 2017), but we think our results demonstrate the capacity of optical image correlation data to revisit pre-modern geodesy earthquakes (before the 1990s) that may have not been intensively investigated in the field after the event. Furthermore, the data used in this study may represent a more typical situation when studying past earthquakes, and thus the processing undertaken and precision of results reported here will be more relevant to the majority of future studies. Our results also highlight the value that remotely-sensed near-field surface displacements can have in guiding field investigations following large earthquakes.

\subsubsection{Zirkuh earthquake}

Fig. 9 compares the surface rupture trace of the Zirkuh earthquake obtained from field mapping (Berberian et al. 1999), with the Z1, Z2, Z3 and KB2 north-south optical surface displacement fields (Fig. 3 and $\mathrm{S} 5$ in supporting information), as well as the Z4 N12 SAR surface displacement field (Fig. 5). All datasets show broadly the same trace of the surface rupture: the northern part is curved (Korizan section), then the fault strike changes and continues broadly at $\mathrm{N} 150^{\circ}$ until the end of the rupture. However in the south, neither the Z3 optical or the Z4 SAR surface displacement fields show the NW-SE southernmost segment of the main rupture, or the two small segments located either side of the fault which were mapped in the field. In the north, the end of the rupture is also not well resolved by our data because the displacements drop below our detection threshold $(\sim 1 \mathrm{~m})$. In the Mirabad section, the western branch has not been mapped during field investigation (Berberian et al. 1999) even though it is located at the southern continuity of the Cheshmeh Shahtut segment (Fig. 3b) and is not visible in the Z4 or the NS KB2 displacement fields. Furthermore, profile BB' on the EW displacement field (Fig. 4b), shows a large peak at the location of the western branch that cannot be interpreted as a coseismic offset. We thus conclude the EW and NS signal observed in the Mirabad section on the optical surface displacement data is not tectonic (Fig. 3b), and possibly results from differences in sunshading between the images, coupled with small topographic residuals.

In order to quantify the variation of surface slip along the rupture of the Zirkuh earthquake, we examine 55 fault-perpendicular displacement profiles spaced every $2 \mathrm{~km}$ along the NS and EW optical displacement components (Z1, Z2 and Z3), and the LOS component from the InSAR-based model. The high level of noise on the $\mathrm{Z} 4 \mathrm{~N} 12^{\circ}$ surface displacement field does not allow us to measure a profile every $2 \mathrm{~km}$; we therefore measure only 25 profiles from this dataset. The various offsets are shown together in Fig. 10, along with the along-strike and vertical field offsets measured by Berberian et al. (1999).

Comparing these offsets is not straightforward. However, we think the comparison between the NS and N12 ${ }^{\circ}$ azimuth offsets is reasonable, despite the small difference in azimuth. Due to the 


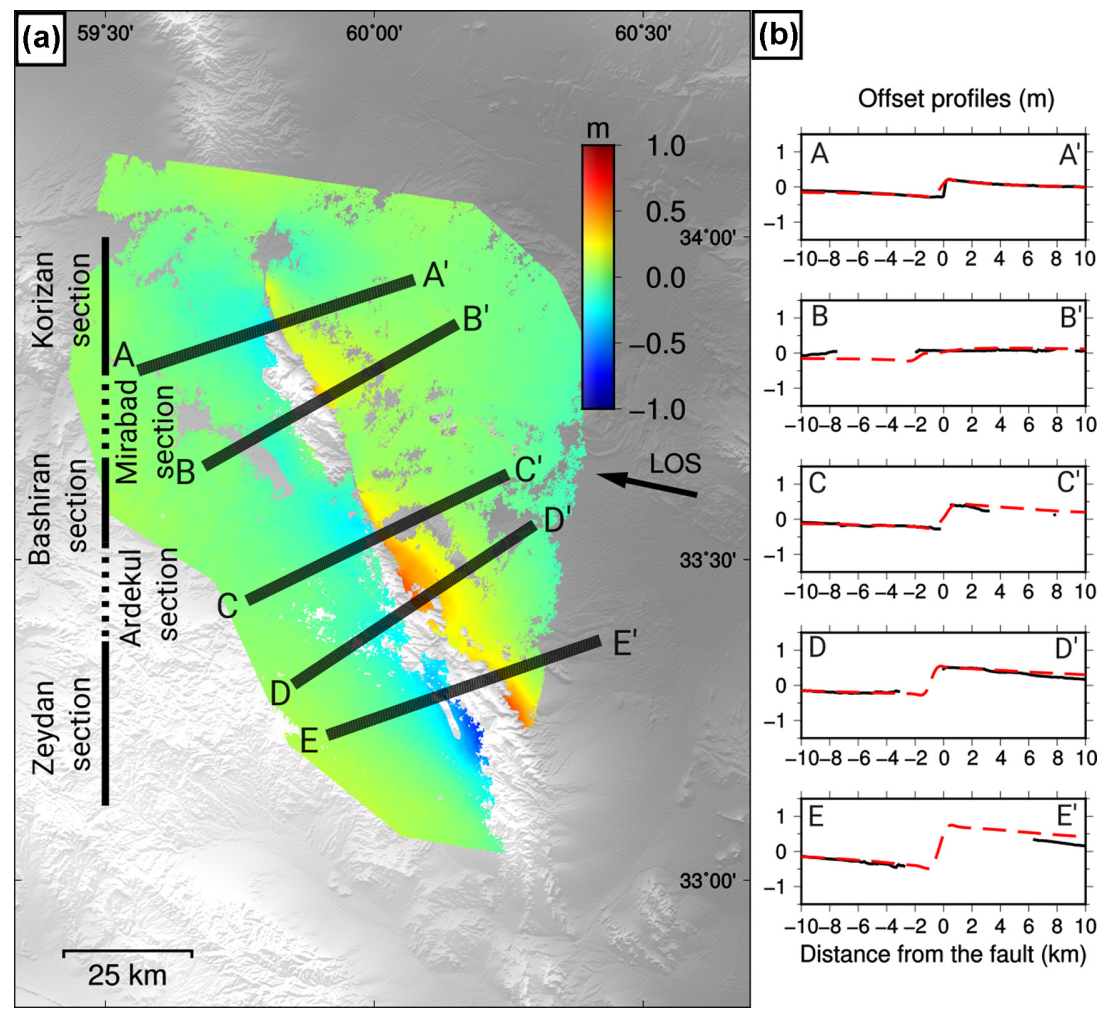

Figure 6. (a) Zirkuh earthquake LOS surface displacement field (m) measured by InSAR (Sudhaus \& Jonsson 2011). Positive displacement indicates a ground motion towards the satellite (black arrow). The grey boxes represent the location of the profiles shown in (b). On the left of the figure, the thick black lines delimit sections of high surface displacement gradient and the dashed lines delimit sections of low surface displacement gradient. (b) Fault-perpendicular profiles. The thick black line is the stack of 12 profiles on a 2-km-wide box and the dashed red line is model predictions based on InSAR data (Sudhaus \& Jonsson 2011).

satellite LOS and the fault strike, the amplitude of the displacement is expected to be 2-6 per cent smaller than the amplitude of the NS displacement. Because of the average fault strike, which is roughly in the NS direction as well, we may compare along-strike field offsets with our measured offsets. Finally, the modeled-LOS displacement offsets across the fault are from a different orientation and rather provide information on the vertical component of the displacement (see Section 4.2.3). We thus make our comparison carefully, and mostly restrict the analysis to a qualitative one.

The curve of NS fault offsets along the fault (Fig. 10b) shows three zones of maximum fault offsets separated by two zones of small fault offsets. The three zones of large NS fault offsets are characterized by three rather symmetrical ellipses with similar maximum amplitude $(2.67 \pm 0.8,2.32 \pm 0.84$ and $2.77 \pm 0.56 \mathrm{~m}$, respectively, from North to South). In the two zones of small NS fault offsets, the offset amplitude decreases to zero. The data allow a precise localization of these zero offsets: at about $25 \mathrm{~km}$ along the fault, in the Mirabad section, and at $60-70 \mathrm{~km}$ along the fault, in the Arkedul section. The offset error is larger in the first $70 \mathrm{~km}$ because of the higher level of noise due to temporal decorrelation in the Z1 and $\mathrm{Z} 2$ displacement fields compared to the $\mathrm{Z} 3$ one as discussed in Section 4.2.1. The N12 offsets confirm the large scale pattern, in particular the NS optical and N12 ${ }^{\circ}$ SAR offsets agree well from 55 to $95 \mathrm{~km}$ (within the error). However, near $35 \mathrm{~km}$, the $\mathrm{N} 12^{\circ}$ offsets are significantly higher than the NS optical ones. The source of this small discrepancy is unclear.

In general, the along-strike field offsets show the three regions of largest displacements. However, the along-strike curve is smoother, with smaller maximum offsets $(2.1,1.90$ and $2.23 \mathrm{~m}$, respectively, from north to south), but higher offsets (up to $1.2 \mathrm{~m}$ ) in the Mirabad and Ardekul sections than in the NS offset curve. In the Mirabad section, the surface rupture has been mapped in the field with four small segments on which the offsets do not exceed $1.2 \mathrm{~m}$ and in between where the offsets are zero. These small offsets occur over small distances which explain why the surface rupture trace is not clearly visible in the optical displacement data. In the Ardekul section, the NS and $\mathrm{N} 12^{\circ}$ offsets are in agreement and close to zero, although the field offsets reach $1.10 \mathrm{~m}$. The Ardekul section is described by Berberian et al. (1999) as a $800 \mathrm{~m}$ wide shear zone with distributed deformation on secondary faults. Thus the field offsets in this zone could also have been observed not in a continuous way but rather at discrete locations.

The slip-curve of the EW offsets (Fig. 10c) shows a similar pattern to the NS offset curve, mainly because of the two obvious minima localized in the Mirabad and Ardekul sections (at about 26 and $60 \mathrm{~km}$, respectively). The amplitude of the EW offsets are much smaller (less than $1 \mathrm{~m}$ ), except in the Zeydan section (Fig. 10c) where they show a significant apparent eastward movement east of the fault. The EW offsets increase progressively reaching a maximum of $2.08 \pm 0.56 \mathrm{~m}$ at $\sim 90 \mathrm{~km}$ along the fault and decrease rapidly to $0.44 \pm 0.50 \mathrm{~m}$ at $95 \mathrm{~km}$ along the fault. The modeled-LOS fault offsets can also be divided in three zones but with some differences in the along-strike slip pattern. The first minimum is located at the southern end of the Mirabad section (at about $40 \mathrm{~km}$ along the fault). Also, a plateau would better describe the modeled-LOS offset variation in the Bashiran section than a bump with no decrease in the Ardekul section. They increase at the Ardekul-Zeydan boundary up to $\sim 90 \mathrm{~km}$ along the fault to finally decrease rapidly near $95 \mathrm{~km}$ 

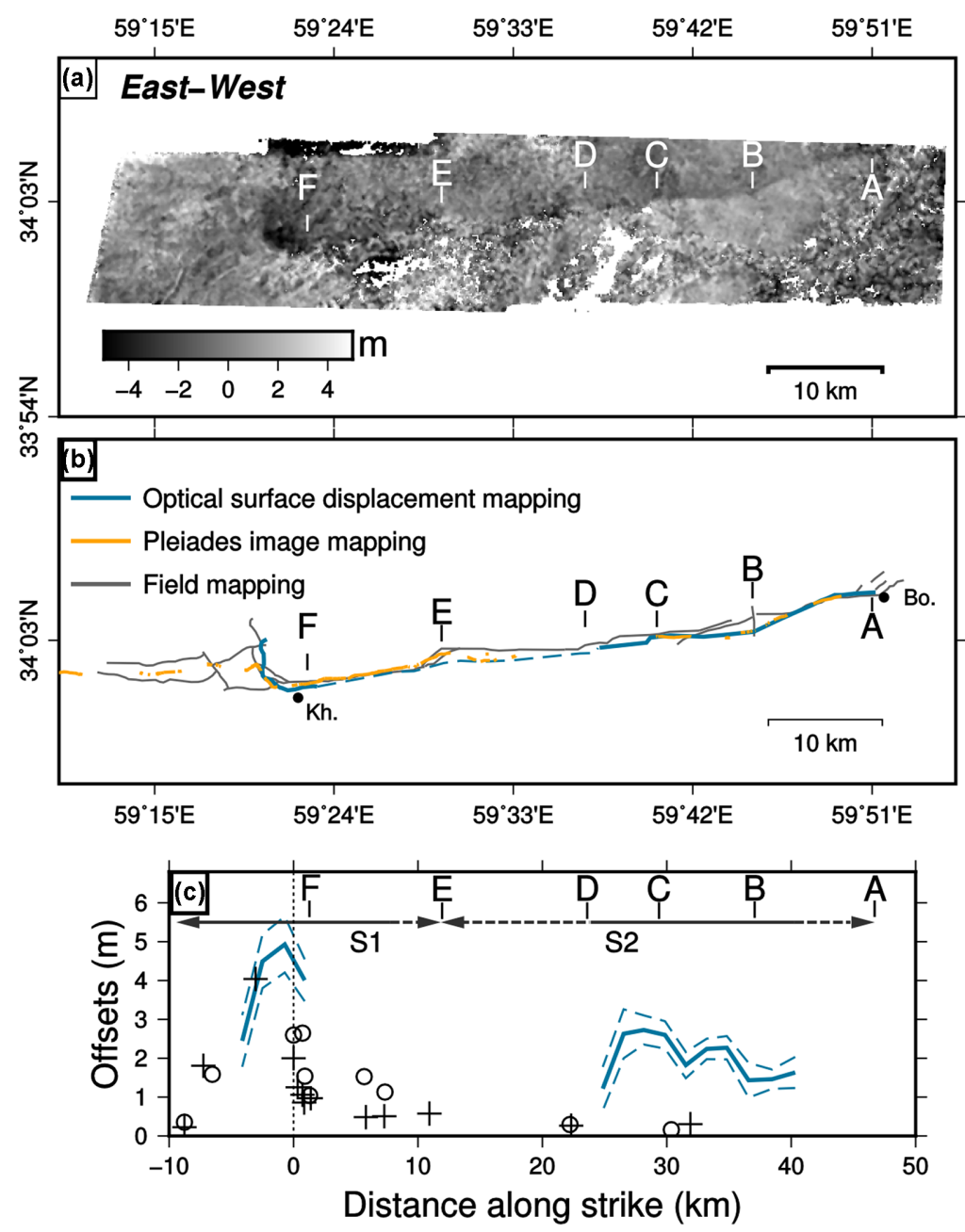

EW optical offsets

○ Along-strike field offset

+ Ver. field offset

Figure 7. (a) EW surface displacement field for the Khuli-Boniabad earthquake. (b) Comparison of the surface rupture traces determined from field investigation (Nowroozi \& Mohajer-Ashjai 1980), from optical image correlation, and from 0.5 m-resolution Pléiades image and 2-m shaded DEM (c) Fault offsets: comparison between along-strike and vertical (Ver.) field offsets and EW offsets from optical image correlation. The black arrows delimit the two main segments of the Khuli-Boniabad earthquake (segments S1 and S1). The $0 \mathrm{~km}$ is located at the longitude of Khuli. Note that offsets located at negative distance are measured on the NS small segment.

along the fault, as the EW offsets (see Fig. 10b). We thus conclude that the modeled-LOS fault offsets reflect the existence of important vertical surface displacements and dip-slip motions on the fault in the Zeydan section, and in the southern part of the Mirabad and Ardekul section where horizontal offsets are minimal. It also confirms that a part of the vertical surface displacement is projected in the Z3 EW surface displacement field (see Section 4.2.1).

To summarize, the whole data sets allow characterizing three main segments where deformation is localized and the slip high on the fault rupture trace. These segments are separated by zones of distributed deformation along with reduced total slip across the fault zone. Significant vertical displacements are observed at each intersegment and in the Zeydan section. These vertical displacements are growing from north to south with a maximum on the Zeydan section.

\subsection{Insights into the $1979 M_{\mathrm{w}} 6.6$ Korizan earthquake}

The KB2 displacement field of the Khuli-Boniabad earthquake covers also the northern part of the Abiz fault (Fig. 1). Thus, we can compare the surface displacement field in the northern part of the Abiz fault along the Korizan section over two different periods (Fig. 11). The first period covers 1976-2017 (NS KB2 displacement field, Tables 1 and 2) and the second 1991-2005 (Z1, Tables 1 and 2). Note that we do not show the comparison between the 1976-1991 and 1991-2005 displacement fields because of strong illumination artifacts in the 1976-1991 correlation results. The surface rupture trace of the curved fault along the Korizan section is visible in both the 1976-2017 and 1991-2005 surface displacement fields (Fig. 11). However, the amplitude of the displacement offsets across the fault varies, as shown in Figs 11(c) and (d). This figure shows three profiles crossing the Abiz fault trace for the two periods along with the measured fault displacement offsets.

The 1976-2017 offsets are higher than the 1991-2005 offsets in the north and progressively decrease southwards until they are equal within the uncertainty. This phenomenon cannot be explained by post-seismic deformation following the Zirkuh earthquake. Indeed, the 1991-2005 surface displacement field includes the first $8 \mathrm{yr}$ of post-seismic deformation. The largest part of post-seismic deformation by far should be included in the period immediately following 

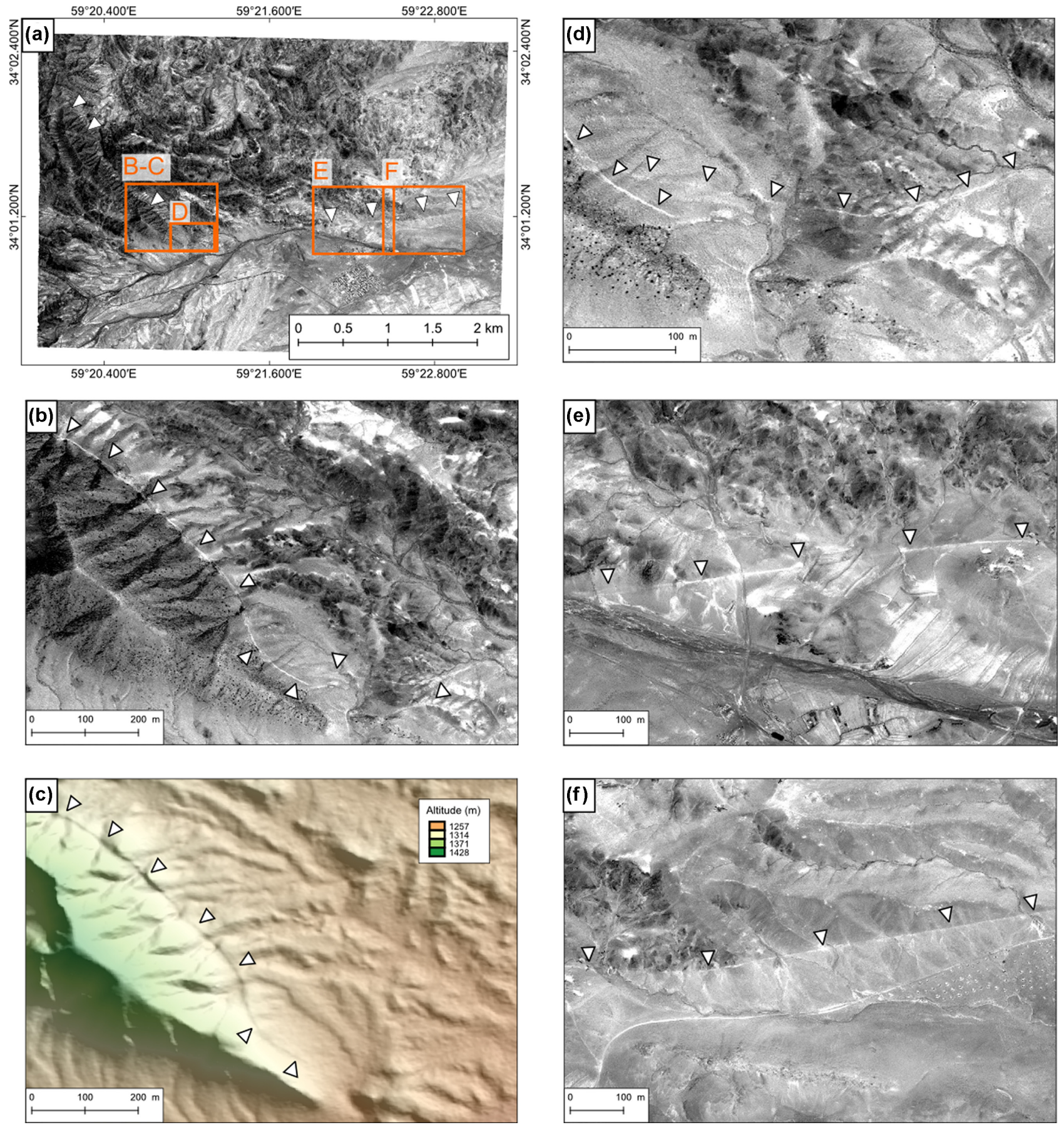

Figure 8. (a) $0.5 \mathrm{~m}$ Pléiades image showing the surface rupture trace, on the western part of the fault, where the fault bends to the north. Rectangles in (a) indicate the location of $(\mathrm{b}-\mathrm{f})$. On each figure, the white triangles highlight the surface rupture. (b) Close-up view showing details of the surface rupture at the fault bend. (c) Shaded version of the 2-m Pléiades DEM of the same area than (b). (d-f) Close-up view showing details of the surface rupture where it is mainly strike-slip.

the mainshock. Moreover, the 2005-2017 displacement field does not show offsets across the Abiz fault. Thus, the offset difference is probably due to another seismic event that may have broken the Abiz fault between 1976 and 2017. The only reported earthquake that has broken this part of the Abiz fault up to the surface between 1976 and 1991 is the $1979 M_{\mathrm{w}} 6.6$ Korizan earthquake. A surface rupture, located further north near the connection between the Abiz and the Dasht-e-Bayaz faults was also reported and has been produced either by the Khuli-Boniabad earthquake or by the Kalat-e-Shur earthquake (see Section 2.1). However, reported displacements for this rupture section are too low [a few centimetres only, Nowroozi \& Mohajer-Ashjai (1980)] to be detectable in our data. The offsets likely result from the $M_{\mathrm{w}} 6.6$ Korizan earthquake. It means that this earthquake would have produced up to $\sim 2.60 \mathrm{~m}$ of surface offset, although only $1 \mathrm{~m}$ has been measured in the field (Berberian $\&$ Yeats 1999). Although such a large offset could be surprising for an $M_{\mathrm{w}} 6.6$ earthquake, an offset of $\sim 2 \mathrm{~m}$ was observed for the 2016 October $30 M_{\mathrm{w}} 6.5$ earthquake in Italy (INGV 2016) and offsets 


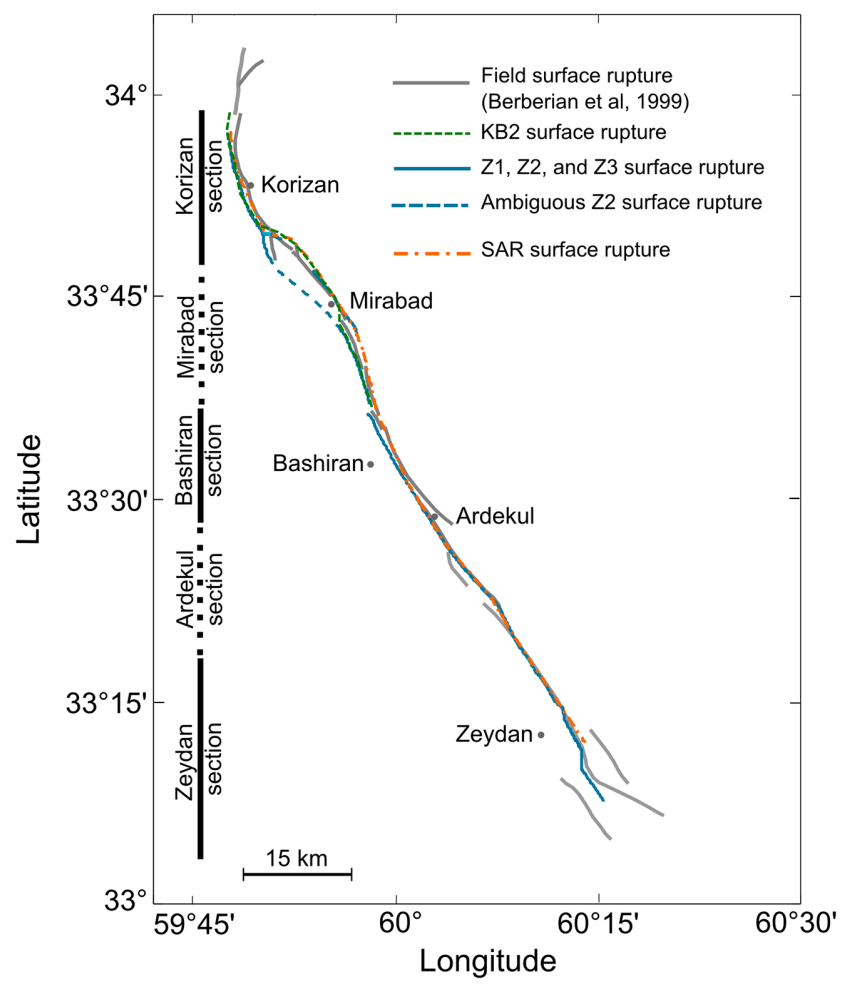

Figure 9. Surface rupture trace of the Zirkuh earthquake from field mapping (black line), optical image correlation data (red and green lines) and SAR image correlation data (blue line).

reaching $45 \mathrm{~cm}$ were observed for a $M_{\mathrm{w}} 5$ strike-slip earthquake in the Ecuadorian Andes (Champenois et al. 2017).

\subsection{Surface displacement field, fault segmentation, and rupture propagation}

The variation in slip along-strike of the Khuli-Boniabad and Zirkuh surface ruptures allows us to characterize each rupture into several segments, with the inter-segments located in the zones of low slip. We examine the correlation between inter-segment location and fault geometry to understand how geometry may impact rupture propagation during each earthquake. Indeed, geometrical complexities, like fault bends or step-overs, are known to impede or arrest the propagation of ruptures (King \& Nabelek 1985; Wesnousky 2006). Localized coseismic surface displacements are generally lower in zones of structural complexity, and has been observed for many earthquakes (e.g., Clark 1972; Liu-zeng et al. 2009; Wei et al. 2011; Choi et al. 2012; Zinke et al. 2014; Milliner et al. 2015, 2016).

The Khuli-Boniabad earthquake broke two main segments of the eastern part of the Dasht-e-Bayaz fault. The eastern end of the S2 segment is simply delimited by the end of the Dasht-e-Bayaz fault. We cannot discriminate the precise location of the inter-segment between S1 and S2 because of a lack of along-strike offsets. However, the field mapping of the rupture trace shows an extensive relay zone between the two zones of high displacement (point E, Fig. 7b) that could be where localized displacement is minimum. Finally, the segment S1 is delimited to the west by the NS-striking part of the rupture. Indeed, the combined offset measurements do not show significant displacement to the west of this NS segment (Fig. 7b). Considering that the rupture nucleated in the east and propagated westward, it thus seems that the fault bend and thrust behaviour of this section have acted as a geometric and mechanical barriers that halted the rupture propagation during the Khuli-Boniabad earthquake.

Despite no significant offsets being observed west of the fault bend in the optical correlation data, a surface rupture in this area was mapped in the field. This part of the fault had already broken during the earlier $1968 M_{\mathrm{w}} 7.1$ Dasht-e-Bayaz earthquake (Fig. S6 in supporting information) but, as for the Khuli-Boniabad earthquake, only a small offset $(<0.5 \mathrm{~m})$ had been measured on this part of the rupture (minor segment S3 in Fig. S6). Indeed, previous studies indicate that the Dasht-e-Bayaz earthquake broke two main segments of the western part of the Dasht-e-Bayaz fault (Ambraseys \& Tchalenko 1969; Tchalenko \& Ambraseys 1970; Tchalenko \& Berberian 1975, and segments S1 and S2 in Fig. S6). The comparison of the rupture trace with the along-strike slip profile indicates that the main intersegment is located at a large step-over where the earthquake also nucleated, whereas the eastern end of the segment S2 coincides with a major change in fault strike (Fig. S6).

The Zirkuh earthquake broke three main segments of the Abiz fault. The northernmost intersegment (Mirabad section) corresponds to a change in fault strike. In the south, the second intersegment (Ardekul section) is a $800 \mathrm{~m}$ large relay zone that could correspond, at depth, to a sharp change in fault dip (Marchandon et al. 2018). The rapid termination of slip at the southern end of the rupture, as seen in the field, LOS and EW optical correlation data, suggests that the rupture, which nucleated in the northern part of the Abiz fault and propagated southward (Berberian et al. 1999), terminated abruptly at the southern end of the fault. As we see for the Khuli-Boniabad earthquake, the Zirkuh rupture also has been arrested by a considerable barrier corresponding to a large stepover ( $\sim 10 \mathrm{~km})$ with the Avaz-Gazik fault (see Fig. 1b). Finally, the Zirkuh earthquake rebroke the northern part of the Abiz fault that had already ruptured during the $1979 M_{\mathrm{w}}$ 6.6 Korizan earthquake. Such scenarios, where a same segment broke twice over a short period of time, have already been observed elsewhere. For example, the $1979 M_{\mathrm{w}} 6.6$ Imperial Valley earthquake (California, US) broke again a segment that had ruptured during a previous $M_{\mathrm{w}} 7.1$ earthquake in 1940 (King \& Thatcher 1998; Rockwell \& Klinger 2013). The surface offset curves estimated for both earthquakes on the segment were nearly identical. According to King \& Thatcher (1998), the interseismic loading is sufficient to explain the re-rupture of the segment. For the Korizan and the Zirkuh earthquakes, the maximum offsets are not located at the same place and the interseismic loading is not fast enough to explain the repeated slip. On the re-ruptured segment, the offsets of the Zirkuh earthquake increase southward whereas they increase northward for the Korizan earthquake. Therefore, the repeated rupture during the Zirkuh earthquake could be due to stress readjustments at places that did not slip enough during the Korizan earthquake (Vallée \& Satriano 2014). Moreover, the Zirkuh earthquake produced only minor surface displacement on this part of the fault, and the rupture propagated mainly to the south. Thus, the part of the fault that broke during the Korizan earthquake may have acted like a stress barrier during the Zirkuh earthquake (Aki 1979; Harris \& Simpson 1996; Scholz 2002; Moreno et al. 2010).

\subsection{Coseismic rupture, long-term fault properties and seismic hazard in th NE Lut}

The Dasht-e-Bayaz and Abiz faults share some similarities: (1) they are strike-slip faults, (2) they can generate large earthquakes $(M>$ 7), (3) they do not show any evidence of creep and (4) they have 

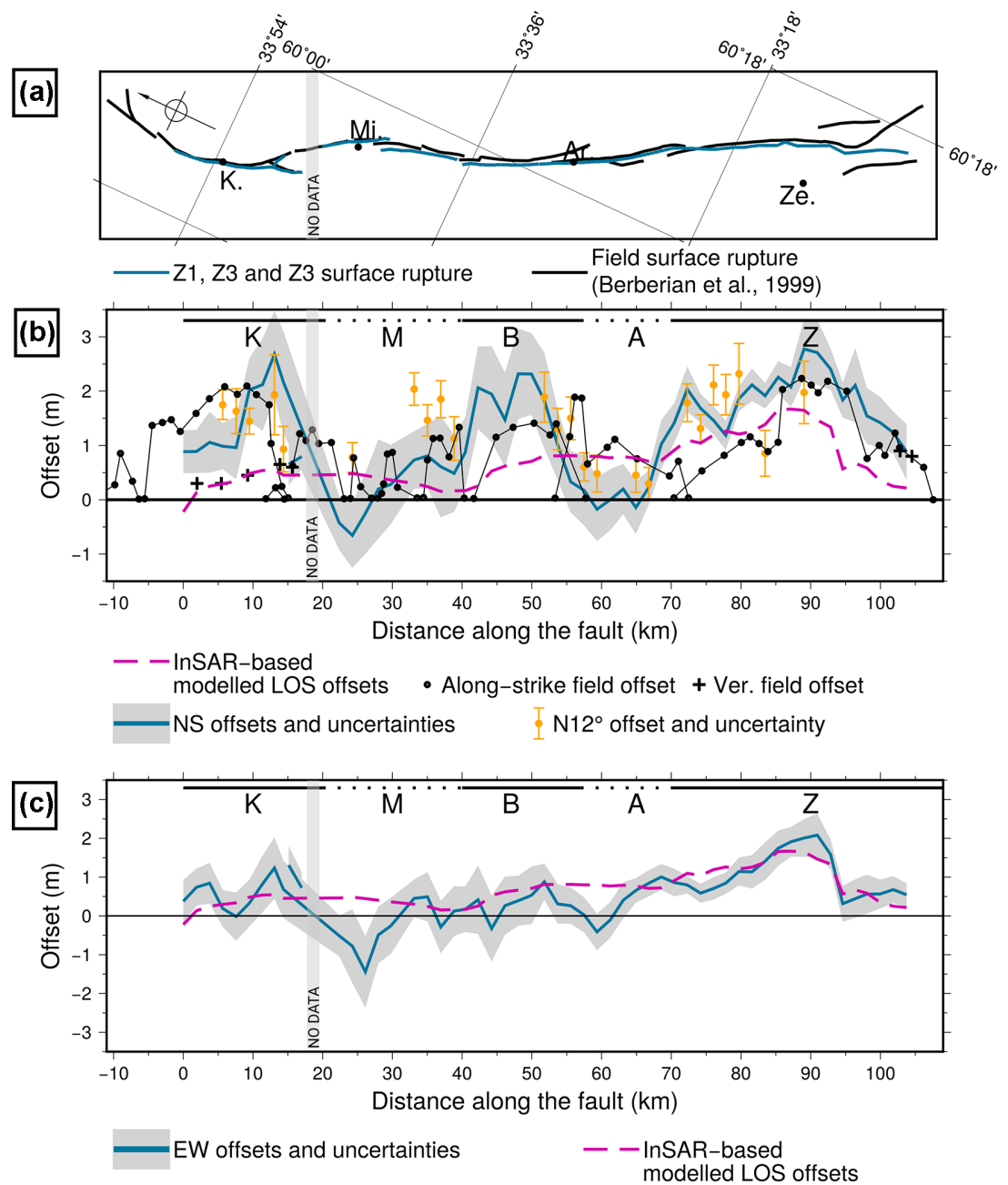

Figure 10. Offsets along the fault of the Zirkuh earthquake. The offsets are estimated by fitting linear regressions to the surface displacement profiles on either side of the fault and measuring the surface displacement difference of the linear regression across the fault. The error of the estimated fault offset is given by the root mean square of standard deviations of the linear regressions on each side of the fault.(a) Surface rupture trace from field investigations (Berberian et al. 1999) and NS optical displacement fields. K, Mi, Ar and Ze are the location of Korizan, Mirabad, Ardekul and Zeydan cities respectively. (b) The thick blue line and the grey envelop represent the NS optical offsets and their uncertainties respectively. The orange points are the SAR N12 offsets, the black points the horizontal field offsets measured by Berberian et al. (1999) and the pink dashed line the modeled-LOS offsets. (c) The thick blue line and the grey envelop represent the EW optical offsets and their uncertainties, respectively. The pink dashed line is the modeled-LOS offsets. On each figure, K, M, B, A and Z mean Korizan, Mirabad, Bashiran, Ardekul and Zeydan sections, respectively. The light grey area labelled "NO DATA" is the zone no covered by the optical data (Fig. 1).

roughly the same length (150 km versus $125 \mathrm{~km}$ for the Dasht-eBayaz and Abiz faults, respectively). However, they did not break the same way. The Dasht-e-Bayaz fault did not break along its entire length (instead breaking $110 \mathrm{~km}$ over two earthquakes), whereas the Abiz fault broke entirely during the Zirkuh earthquake. We therefore discuss the pattern of coseismic surface ruptures in relation to the long-term fault properties to better understand this difference in failure style.

According to Manighetti et al. (2007), structural maturity of faults is an important ingredient controlling rupture extension. As faults mature, the length of coseismic ruptures tends to increase, along with the number of broken segments seen along the fault. We use the maturity criteria of Manighetti et al. (2007) to discuss the characteristics of the 1968, 1979 and 1997 earthquakes with regards to the Dasht-e-Bayaz and Abiz faults. Manighetti et al. (2007) used a combination of four parameters to characterize the maturity of a fault: (1) the total long-term displacement, (2) slip rate, (3) fault length and (4) initiation age.
For the Dasht-e-Bayaz fault, except for the initiation age which is unknown, there are estimates for the other parameters. The cumulative lateral offset on the Dasht-e-Bayaz fault is relatively small ( $\sim 5.5 \mathrm{~km}$, Walker et al. (2004)). Two consistent Holocene slip rates of minimum $2.5 \mathrm{~mm} \mathrm{yr}^{-1}$ have been estimated from the datation of lateral offset of man-made features (Fattahi 2015) and lake-beds (Fattahi et al. 2015). Geodetic data would suggest a possibly lower slip rate at the present day (Walpersdorf et al. 2014). The Dasht-eBayaz fault is about $150 \mathrm{~km}$ long.

The Abiz fault, on the other hand, is located at the north end of the 600-km-long Sistan Suture Zone. Walker \& Jackson (2004) have estimated $90 \mathrm{~km}$ of cumulated lateral offset at the latitude $30^{\circ} \mathrm{N}$. In the central Sistan Suture Zone (lat. $31.5^{\circ} \mathrm{N}$ to lat. $32.5^{\circ} \mathrm{N}$ ), the Holocene slip-rate estimate is $8 \pm 4 \mathrm{~mm} \mathrm{yr}^{-1}$ (Meyer \& Dortz 2007), consistent with the geodetic data $\left(5.6 \pm 0.6 \mathrm{~mm} \mathrm{yr}^{-1}\right.$, Walpersdorf et al. 2014). The initiation age of the Abiz fault is unknown.

Based on these maturity parameters, the Abiz fault would be deemed more mature than the Dasht-e-Bayaz fault, and thus 

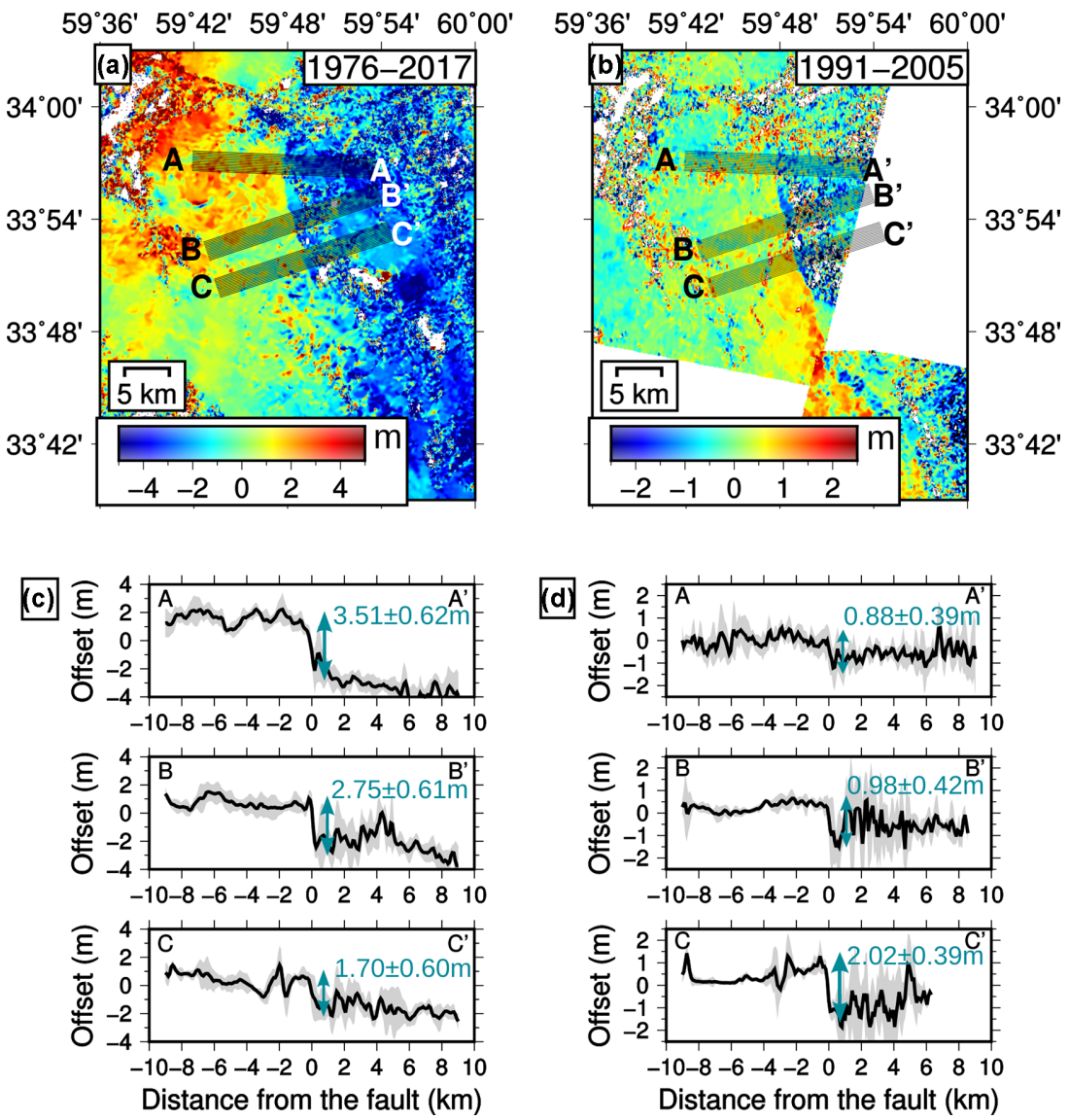

Figure 11. NS displacement field of the northern part of the Abiz fault between (a) 1976-2017 and (b) 1991-2005. Fault-perpendicular profiles measured on the NS displacement field of (c), (a) and (d) (b). In (c-d), each profiles is a stack of 12 profiles in a 2-km-wide box.

may rupture more (and longer) segments during an earthquake (Manighetti et al. 2007). Indeed, both the Dasht-e-Bayaz and KhuliBoniabad earthquakes broke two main segments of $\sim 25 \mathrm{~km}$ length, whereas the Zirkuh earthquake broke three main segments of $\sim 40 \mathrm{~km}$ length. Moreover, the westernmost segment of the Dashte-Bayaz fault (Fig. S7a in the supporting information) remains unruptured during this sequence, whereas the entire Abiz fault broke. The various segments of the Abiz fault may therefore be more connected than those of the Dasht-e-Bayaz faults, thus facilitating the propagation of rupture across the inter-segment zones (Manighetti et al. 2007).

An increased level of structural maturity for the Abiz fault is also supported by the comparison of the long-term trace of the Dasht-eBayaz and Abiz faults with the coseismic rupture trace during the three earthquakes. The Zirkuh rupture trace is consistent with the long-term trace of the Abiz fault (Fig. S7b), whereas the Dasht-eBayaz and Khuli-Boniabad rupture traces do not follow the longterm trace of the Dasht-e-Bayaz fault for 60 per cent of the fault length (Fig. S7a). Finally, according to Manighetti et al. (2007), the maturity of a fault also influences the maximum coseismic slip; over the same length, a mature fault will produce a smaller maximum slip than an immature fault. In our case, the Dasht-e-Bayaz and Khuli-Boniabad earthquakes have a maximum surface slip around $4.5 \mathrm{~m}$ with a rupture length of $\sim 60 \mathrm{~km}$, whereas the Zirkuh rupture length and maximum coseismic slip are $125 \mathrm{~km}$ and $\sim 3.5 \mathrm{~m}$, respectively.

The NE Lut sequence broke the 75 per cent of the Dasht-e-Bayaz fault and the entire Abiz fault between 1968 and 1997. No major earthquakes have occurred in the NE Lut since this time. However, these two faults belong to a larger strike-slip fault system, and these three $M>7$ earthquakes will have generated some stress changes on the surrounding fault segments and surrounding medium (e. g. Stein et al. 1997). First, the western 30-km-long segment of the Dashte-Bayaz fault that did not break during the sequence is probably more prone to rupture (Fig. S7). In the event only this segment ruptures, it will probably not produce a $M>7$ large earthquake (Wells \& Coppersmith 1994), but may generate a moderate $(M>$ 6) earthquake (nevertheless, still devastating for populations living close to the fault trace). Second, in the framework of the East Lut fault system, the 200-km-long Avaz-Gazik fault (Fig. S7c) forms the southern continuity of the Abiz fault to the south and has likely been stressed by the Zirkuh earthquake. Only two major historical earthquakes $(M \sim 7)$ have been reported in the East Lut area and occurred further to the west and to the south of the Avaz-Gazik fault (Fig. S7c), on the Nauzad and Nosratabad faults in 1493 and 1838, respectively (Berberian \& Yeats 1999). Hence, no large historical earthquakes are known to have occurred on this section of the East Lut fault system (Ambraseys \& Melville 1982) since at least $500 \mathrm{yr}$. Therefore, the Avaz-Gazik fault presents also a high risk to break and could generate a major destructive earthquake $(M \geq 7)$.

\section{CONCLUSION}

In this study, we use correlation of historical and recent optical satellite image and correlation of SAR amplitude images to measure the surface displacement produced by the three last earthquakes $\left(M_{\mathrm{w}}\right.$ 
$>$ 6.6) of the 1936-1997 NE Lut earthquake sequence. We succeed for the first time to measure the surface displacement field of the $1979 M_{\mathrm{w}} 7.1$ Khuli-Boniabad earthquake and to detect fault offsets produced by the $1979 M_{\mathrm{W}} 6.6$ Korizan earthquake (up to $2.60 \mathrm{~m}$ ). We also complement the surface displacement observations of the $1997 M_{\mathrm{w}} 7.2$ Zirkuh earthquake, with dense near-field measurements. We find that the $1979 M_{\mathrm{w}} 7.1 \mathrm{Khuli}-\mathrm{Boniabad}$ event broke two main segments of the Dasht-e-Bayaz fault, whereas the $1997 M_{\mathrm{w}} 7.2$ Zirkuh event broke three main segments of the Abiz fault. For both earthquakes, the inter-segments correlate with geometric complexities along the fault, such as fault bends or large step-overs. Both earthquake ruptures were arrested by strong geometrical barriers leading to significant vertical displacements at the end of each rupture. Moreover, for both earthquakes, the maximum surface offsets are $\sim 4 \mathrm{~m}$, with a rupture length 50 per cent smaller for the 1979 earthquake than the 1997 one. These two last observations, as well as the number of broken segments, are consistent with differing levels of structural maturity for the two faults, the Dasht-e-Bayaz fault being less mature than the Abiz fault. The comprehensive surface displacement field analysis of these earthquakes should be valuable to constrain the NE Lut earthquake sequence and fault interaction modelling in the future. Finally, our study confirms that historic satellite images are useful for studying surface ruptures of past earthquakes $(<1990$, even moderate ones) and should motivate further exploitation of the vast archive of historical and aerial data to further document surface displacements of past earthquakes (isolated or belonging to a seismic sequence).

\section{ACKNOWLEDGEMENTS}

The study was supported by the Agence Nationale de la Recherche (ANR, French National Research Agency) through the "EarlyPOSTseismic deformation (E-POST)" project under the contract No. ANR-14-CE03-0002. The Satellite Pour l'Observation de la Terre (SPOT) and Pléiades images are Astrium products and have been purchased via the Incitation à l'utilisation Scientifique des Images SPOT (ISIS) French program. Advanced Spaceborne Thermal Emission and Reflection Radiometer (ASTER) Global Digital Elevation Model (GDEM) is a product of the Ministry of Economy, Trade, and Industry (METI) of Japan and the United States National Aeronautics and Space Administration (NASA), and was obtained through the Reverb ECHO website. Shuttle Radar Topography Mission (SRTM) DEM is a product of NASA and the National Geospatial-Intelligence Agency (NGA) and was obtained through the United States Geological Survey (USGS) EarthExplorer website. Keyhole 9 (KH-9) data was obtained through the USGS EarthExplorer website. This work contains modified Copernicus Sentinel data 2017, processed by the European Space Agency (ESA). All optical images were processed using the Co-registration of Optically Sensed Images and Correlation (COSI-Corr) software (Leprince et al. 2007), which is a plug-in for the Environment for Visualizing Images (ENVI) software package. Several figures were created with the Generic Mapping Tools (GMT) software (Wessel et al. 2013). We thank I. Manighetti for fruitful discussions on long-term fault properties. We are grateful to R. Walker, an anonymous reviewer and Editor K. Heki for their constructive and thorough comments that greatly helped us improve our manuscript.

\section{R E F E R E N C ES}

Aki, K., 1979. Characterization of Barriers on an Earthquake Fault, J. geophys. Res., 84(9), 6140-6148.

Ambraseys, N.N. \& Melville, C., 1982. A History of Persian Earthquakes, Cambridge University Press.

Ambraseys, N.N. \& Tchalenko, J.S., 1969. The dasht-e Bayaz (Iran) earthquake of August 31, 1968: a field report, Bull. seism. Soc. Am., 59(5), $1751-1792$.

Ayoub, F., Leprince, S. \& Avouac, J.-P., 2009. Co-registration and correlation of aerial photographs for ground deformation measurements, ISPRS J. Photogram. Rem. Sens., 64(6), 551-560.

Ayoub, F., Leprince, S. \& Avouac, J.-P., 2015. User's guide to COSI-CORR co-registration of optically sensed images and correlation, in COSI-Corr User's Manual, California Institute of Technology, pp. 1-49.

Berberian, M. \& Yeats, R.S., 1999. Patterns of historical earthquake rupture in the Iranian Plateau, Bull. seism. Soc. Am., 89, 120-139.

Berberian, M., Jackson, J.A., Qorashi, M., Khatib, M.M., Priestley, K. \& Talebian, M., 1999. The 1997 May 10 Zirkuh (Qa'enat) earthquake (Mw 7.2): faulting along the Sistan suture zone of eastern Iran, J. geophys. Int., 136(3), 671-694.

Buades, A., Coll, B. \& Morel, J.-M., 2008. Nonlocal image and movie denoising, Int. J. Comput. Vis., 76, 123-139.

Champenois, J., Baize, S., Vallee, M., Jomard, H., Alvarado, A., Espin, P., Ekström, G. \& Audin, L., 2017. Evidences of surface rupture associated with a low-magnitude (Mw 5.0), J. geophys. Res.: Solid Earth, 122(10), 8446-8458.

Choi, J.-H., Jin, K., Enkhbayar, D., Davvasambuu, B., Bayasgalan, A. \& Kim, Y.-S., 2012. Rupture propagation inferred from damage patterns, slip distribution, and segmentation of the $1957 \mathrm{Mw} 8.1$ Gobi-Altay earthquake rupture along the Bogd fault, Mongolia, J. geophys. Res, 117, $1-24$.

Clark, M.M., 1972. Surface rupture along the Coyote Creek fault, in the Borrego Mountain Earthquake of April 9, 1968, U. S. Geol. Sur. Prof. Paper, 787, 55-86.

Copley, A., Hollingsworth, J. \& Bergman, E., 2012. Constraints on fault and lithosphere rheology from the coseismic slip and postseismic afterslip of the 2006 Mw 7.0 Mozambique earthquake, J. geophys. Res., 117, 1-16.

Engdahl, E.R., Jackson, J.A., Myers, S.C., Bergman, E.A. \& Priestley, K., 2006. Relocation and assessment of seismicity in the Iran region, J. geophys. Int., pp. 761-778.

Fattahi, M., 2015. OSL dating of the Miam Qanat (KARIZ) system in NE Iran, J. Arch. Sci., 59, 54-63.

Fattahi, M., Walker, R., Khatib, M.M., Zarrinkoub, M. \& Talebian, M., 2015. Determination of slip-rate by optical dating of lake bed sediments from the Dasht-e-Bayaz fault, NE Iran, Geochronometria, 42, 148-157.

Freed, A.M., 2005. Earthquake triggering by static, dynamic, and postseismic stress transfer, Annu. Rev. Earth planet. Sci., 33, 335-367.

Haghipour, A. \& Amidi, M., 1980. The November 14 to December 25, 1979 Ghaenat Earthquakes of Northeast Iran and their Tectonic Implications, Bull. seism. Soc. Am., 70(5), 1751-1757.

Harris, R.A. \& Simpson, R.W., 1996. In the shadow of 1857-the effect of the great Ft. Tejon earthquake on subsequent earthquakes in southern California, Geophys. Res. Lett., 23(3), 229-232.

Hollingsworth, J., Leprince, S., Ayoub, F. \& Avouac, J.P., 2012. Deformation during the 1975-1984 Krafla rifting crisis, NE Iceland, measured from historical optical imagery, J. geophys. Res.: Solid Earth, 117, 1-24.

Hollingsworth, J., Leprince, S., Ayoub, F. \& Avouac, J.-P., 2013. New constraints on dike injection and fault slip during the 1975-1984 Krafla rift crisis, NE Iceland, J. geophys. Res.: Solid Earth, 118, 1-21.

Hollingsworth, J., Lingling, Y. \& Avouac, J.-P., 2017. Dynamically triggered slip on a splay fault in the Mw 7.8, 2016 Kaikoura (New Zealand) earthquake, Geophys. Res. Lett., 44(8), 3517-3525.

INGV, R., 2016. Summary report on the October 30, 2016 earthquake in central Italy Mw 6.5, Tech. rep. 
Kääb, A., Altena, B. \& Mascaro, J., 2017. Coseismic displacements of the 14 November $2016 \mathrm{Mw} 7.8$ Kaikoura, New Zealand, earthquake using the Planet optical cubesat constellation, Nat. Hazard Earth Syst. Sci., 17, 627-639.

King, G. \& Nabelek, J., 1985. Role of fault bends in the Initiation and Termination of Earthquake Rupture, Science, 228(4702), 984-987.

King, N.E. \& Thatcher, W., 1998. The coseismic slip distributions of the 1940 and 1979 Imperial Valley, California, earthquakes and their implications dip slip., J. geophys. Res., 103(B8), 18 069-18 086.

Konca, A.O., Leprince, S., Avouac, J.-P. \& Helmberger, D.V., 2010. Rupture process of the $1999 \mathrm{Mw} 7.1$ Duzce earthquake from joint analysis of SPOT, GPS, InSAR, strong-motion, and teleseismic data: a supershear rupture with variable rupture velocity, Bull. seism. Soc. Am., 100(1), 267-288.

Leprince, S., Barbot, S., Ayoub, F. \& Avouac, J.-P., 2007. Automatic and precise orthorectification, coregistration, and subpixel correlation of satellite images, application to ground deformation measurements, IEEE Trans. Geosci. Rem. Sens., 45(6), 1529-1558.

Liu-zeng, J. et al., 2009. Co-seismic ruptures of the 12 May 2008, Ms 8.0 Wenchuan earthquake, Sichuan: east west crustal shortening on oblique, parallel thrusts along the eastern edge of Tibet, Earth planet. Sci. Lett., 286, 355-370.

Manighetti, I., Campillo, M., Bouley, S. \& Cotton, F., 2007. Earthquake scaling, fault segmentation, and structural maturity, Earth planet. Sci. Lett., 253, 429-438.

Marchandon, M., Vergnolle, M., Sudhaus, H. \& Cavalié, O., 2018. Fault geometry and slip distribution at depth of the $1997 \mathrm{Mw} 7.2$ Zirkuh earthquake: contribution of near-field displacement data, J. geophys. Res.: Solid Earth, 123, 1-21.

Meyer, B. \& Dortz, K.L., 2007. Strike-slip kinematics in Central and Eastern Iran: Estimating fault slip-rates averaged over the Holocene, Tectonics, 26, $1-20$.

Michel, R. \& Avouac, J.-P., 2002. Deformation due to the 17 August 1999 Izmit, Turkey, earthquake measured from SPOT images, J. geophys. Res., 107(B4), 1-6.

Michel, R. \& Avouac, J.-P., 2006. Coseismic surface deformation from air photos: the Kickapoo step over in the 1992 Landers rupture, J. geophys. Res., 111, doi:10.1029/2005JB003776.

Michele, M. et al., 2016. The Amatrice 2016 seismic sequence : a preliminary look at the mainshock and aftershocks distribution, Ann. Geophys., $\mathbf{5 9 ,} 1-8$.

Milliner, C.W.D., Dolan, J.F., Hollingsworth, J., Leprince, S., Ayoub, F. \& Sammis, C.G., 2015. Quantifying near-field and off-fault deformation patterns of the 1992 Mw 7.3 Landers earthquake, Geochem., Geophys., Geosyst., 16(5), 1577-1598.

Milliner, C.W.D., Sammis, C., Allam, A.A., Dolan, J.F., Hollingsworth, J. \& Leprince, S., 2016. Resolving fine-scale heterogeneity of co-seismic slip and the relation to fault structure, Scient. Rep., 6, 1-9.

Moreno, M., Rosenau, M. \& Oncken, O., 2010. 2010 Maule earthquake slip correlates with pre-seismic locking of Andean subduction zone, Nature, 467(7312), 198-202.

Nowroozi, A. \& Mohajer-Ashjai, A., 1980. Faulting of Kurizan and Koli (Iran) earthquakes of November 1979. A field report., Bull. B.R.G.M, IV(2), 97-99.

Pollitz, F., Vergnolle, M. \& Calais, E., 2003. Fault interaction and stress triggering of twentieth century earthquakes in Mongolia, J. geophys. Res, 108(B10), 1-14.

Rockwell, T. \& Klinger, Y., 2013. Surface rupture and slip distribution of the 1940 Imperial Valley Earthquake, Imperial Fault, Southern California: implications for rupture segmentation and dynamics, Bull. seism. Soc. Am., 103(2A), 629-640.

Schlagenhauf, A., Manighetti, I., Benedetti, L., Gaudemer, Y., Finkel, R., Malavieille, J. \& Pou, K., 2011. Earthquake supercycles in Central Italy, inferred from $36 \mathrm{Cl}$ exposure dating, Earth planet. Sci. Lett., 307, 487500 .
Scholz, C.H., 2002. The Mechanics of Earthquakes and Faulting, Cambridge.

Shean, D.E., Alexandrov, O., Moratto, Z.M., Smith, B.E., Joughin, I.R., Porter, C. \& Morin, P., 2016. An automated, open-source pipeline for mass production of digital elevation models (DEMs) from very-highresolution commercial stereo satellite imagery, ISPRS J. Photogram. Rem. Sens., 116, 101-117.

Sieh, K. et al., 2008. Earthquake supercycles inferred from sea-level changes recorded in the Corals of West Sumatra, Science, 322, 1674-1678.

Stein, R.S., Barka, A.A. \& Dieterich, J.H., 1997. Progressive failure on the North Anatolian fault since 1939 by earthquake triggering, J. geophys. Int., 128, 594-604.

Sudhaus, H. \& Jonsson, S., 2011. Source model for the 1997 Zirkuh earthquake $(\mathrm{Mw}=7.2)$ in Iran derived from JERS and ERS InSAR observations, J. geophys. Int., 185(2), 676-692.

Surazakov, A. \& Aizen, V., 2010. Positional accuracy evaluation of declassified Hexagon KH-9 mapping camera imagery, Photogram. Eng. Rem. Sens., 76(5), 603-608.

Tchalenko, J.S. \& Ambraseys, N.N., 1970. Structural analysis of the Dashte-Bayaz (Iran) earthquake fractures, Bull. geol. Soc. Am., 81, 41-60.

Tchalenko, J.S. \& Berberian, M., 1975. Dasht-e Bayaz Fault, Iran: earthquake and earlier related structures in bed rock, Bull. geol. Soc. Am., 86, 703-709.

Vallage, A., Klinger, Y., Grandin, R. \& Bhat, H.S., 2015. Inelastic surface deformation during the $2013 \mathrm{Mw} 7.7$ Balochistan, Pakistan, earthquake, Geology, 43(12), 1079-1082.

Vallée, M. \& Satriano, C., 2014. Ten year recurrence time between two major earthquakes affecting the same fault segment, Geophys. Res. Lett., 41, 1-7.

Vernant, P. et al., 2004. Present-day crustal deformation and plate kinematics in the Middle East constrained by GPS measurements in Iran and northern Oman, J. geophys. Int., 157, 381-398.

Walker, R. \& Jackson, J., 2004. Active tectonics and late Cenozoic strain distribution in central and eastern Iran, Tectonics, 23, 1-24.

Walker, R., Jackson, J. \& Baker, C., 2004. Active faulting and seismicity of the Dasht-e-Bayaz region, eastern Iran, J. geophys. Int., 157, 265-282.

Walker, R.T., Bergman, E.A., Szeliga, W. \& Fielding, E.J., 2011. Insights into the 1968-1997 Dasht-e-Bayaz and Zirkuh earthquake sequences, eastern Iran, from calibrated relocations, InSAR and high-resolution satellite imagery, J. geophys. Int., 187, 1577-1603.

Walpersdorf, A. et al., 2014. Present-day kinematics and fault slip rates in eastern Iran, derived from 11 years of GPS data, J. geophys. Res.: Solid Earth, 119(2), 1359-1383.

Wegmüller, U. \& Werner, C., 1997. Gamma SAR processor and interferometry software, in Proc. the 3rd ERS Symposium, ESA, pp. 1687-1692.

Wei, S. et al., 2011. Superficial simplicity of the 2010 El Mayor-Cucapah earthquake of Baja California in Mexico, Nat.. Geosci., 4(9), 615-618.

Wells, D.L. \& Coppersmith, K.J., 1994. New empirical relationships among magnitude, rupture length, rupture width, rupture area, and surface displacement, Bull. seism. Soc. Am., 84(4), 974-1002.

Wesnousky, S.G., 2006. Predicting the endpoints of earthquake ruptures, Nature, 444, 358-360.

Wessel, P., Smith, W., Scharroo, R., Luis, J. \& Wobbe, F., 2013. Generic mapping tools: improved version released, EOS, Trans. Am. Geophys. Un., 94(45), 409-420.

$\mathrm{Xu}$, X., Tong, X., Sandwell, D.T., Milliner, C.W.D., Dolan, J.F., Hollingsworth, J., Leprince, S. \& Ayoub, F., 2016. Refining the shallow slip deficit, J. geophys. Int., 204, 1867-1886.

Zhou, Y., Walker, R.T., Hollingsworth, J., Talebian, M., Song, X. \& Parsons, B., 2016. Coseismic and postseismic displacements from the $1978 \mathrm{Mw}$ 7.3 Tabas-e-Golshan earthquake in eastern Iran, Earth planet. Sci. Lett., 452, 185-196.

Zinke, R., Hollingsworth, J. \& Dolan, J.F., 2014. Surface slip and off-fault deformation patterns in the $2013 \mathrm{Mw}$ 7.7 Balochistan, Pakistan earthquake: implications for controls on the distribution of near-surface coseismic slip, Geochem. Geophys. Geosyst., 15(12), 5034-5050. 


\section{SUPPORTING INFORMATION}

Supplementary data are available at $G J I$ online.

Figure S1. Illustration of the distortion correction on the KH95001/Sentinel-2 correlation. EW surface displacement field from the correlation of the KH9-5001 image with the Sentinel-2 image (KB2, Tables 1 and 2 in the main paper) (a) before and (b) after the subtraction of a second order polynomial using the detrending tool of COSI-Corr. The detrending allows to remove a long-wavelength trend due to film distortion. Due to uncorrected topographic features, significant topographically correlated noise are visible in the displacement field (area delimited by the orange dashed line). The surface rupture trace is highlighted by orange triangles.

Figure S2. Surface displacement field from the correlation of the KH9-4001 image with the Sentinel- 2 image (KB3 displacement field, Tables 1 and 2 in the main paper) Top panel: EW displacement field. Bottom panel: NS displacement field.

Figure S3. Surface displacement field from the correlation of the KH9-5001 image with the Sentinel- 2 image (KB4 displacement field, Tables 1 and 2 in the main paper) Top panel: EW displacement field. Bottom panel: NS displacement field.

Figure S4. (a) Z3 EW displacement field. (b) Shaded DEM (SRTM $30 \mathrm{~m}$ ) of the same zone. Comparison of figures (a) and (b) shows that the signal in the eastern side of the fault in figure (a) is correlated with the ridge of the mountains in (b). On both figures, the red line highlights the trace of the surface rupture.

Figure S5. NS displacement field from the KB2 correlation (Table 2 in the main paper) covering the northern part of the Abiz fault. The data are the same than in Fig. 11(a) but with a larger extent.

Figure S6. (a) The black line is the surface rupture trace of the Dasht-e-Bayaz earthquake (from Ambraseys \& Tchalenko 1969; Tchalenko \& Ambraseys 1970; Tchalenko \& Berberian 1975) whereas the grey line is the surface rupture trace of the KhuliBoniabad earthquake (Nowroozi \& Mohajer-Ashjai 1980). The blue points locate the Dasht-e-Bayaz (DeB) and Khuli-Boniabad (KB) cities, the black points show the location of the first and last offsets in Fig. S5(b), and the orange star locates the epicentre of the Dashte-Bayaz earthquake (Engdahl et al. 2006) (b) Left-lateral offsets along the fault (from Ambraseys \& Tchalenko (1969) Tchalenko $\&$ Berberian (1975). The along-strike offset variations allow delimiting three segments. The S3 segment showing very small offsets $(<0.5 \mathrm{~m})$, it is considered as a minor segment of the rupture. The fault complexities labelled in Fig. S5(a) (step-over and bend) coincide with the intersegments location.

Figure S7. (a) Comparison of the long-term fault trace of the Dashte-Bayaz fault (black lines, from Walpersdorf et al. 2014) with the rupture trace of the 1968 Dasht-e-Bayaz [green lines, (Ambraseys \& Tchalenko 1969); (Tchalenko \& Ambraseys 1970); Tchalenko \& Berberian (1975)] and Khuli-Boniabad (red lines, this study) earthquakes. (b) Comparison of the long-term fault trace of the Abiz fault [black lines, from Walpersdorf et al. (2014)] with the rupture trace of the 1997 Zirkuh earthquake (blue lines, this study). (c) Long-term fault trace of the segments of the Sistan Suture zone (from Walpersdorf et al. (2014)). DeB, N, AG, EN, WN, KAH, NOS mean Dasht-e-Bayaz, Nauzad, Avaz-Gazik, East Neh, West Neh, Kahurak and Nosratabad, respectively. The grey circle shows the meizoseismal zones of the $\sim M 71493$ and 1838 historical earthquakes (from Berberian \& Yeats 1999).

Please note: Oxford University Press is not responsible for the content or functionality of any supporting materials supplied by the authors. Any queries (other than missing material) should be directed to the corresponding author for the article. 